\title{
New method of temperature and conductivity sensor calibration with improved efficiency for screening SBE41 CTD on Argo floats
}

\author{
Shigeki Hosoda ${ }^{1 *}$, Mizue Hirano ${ }^{1}$, Takayuki Hashimukai², Satoko Asai ${ }^{2}$ and Noriko Kawakami²
}

\begin{abstract}
The global ocean monitoring system would benefit from improvements in the efficiency of Conductivity, Temperature, and Depth Device (CTD) sensor screening. Here, we describe the development of a new screening system, J-Calibration, for use with the SBE41 CTD sensor on the Argo float (Sea Bird Scientific). This new system has crucial advantages over the traditional SBE-Calibration system. First, J-Calibration does not require removal of the CTD sensor unit from the Argo float body to operate in a laboratory. This feature enables technicians or operators to more efficiently check the Argo target accuracies $\left( \pm 0.005^{\circ} \mathrm{C}\right.$ for temperature and \pm 0.01 PSS-78 for salinity) and allows the manufacturer's warranty to remain intact. This also allows for a more efficient basic screening system which maintains screening accuracy without the need for specialized technicians. J-Calibration reduces the screening time to 1/6th that of SBE-Calibration and does not require the preparation of large amounts of artificial seawater. J-Calibration uses 1/23rd of the volume of seawater compared to SBE-Calibration by examining calibration at only 1 temperature point $\left(22^{\circ} \mathrm{C}\right)$, whereas SBE-Calibration requires 7 points to achieve calibration. The J-Calibration system does require careful temperature control of the artificial seawater as it is critical to maintain a uniform water temperature throughout the experiments. To satisfy this, using a vinyl greenhouse and covering sensors with adiabatic materials and cooling packs are effective. In comparison with the accuracy and system stability of SBECalibration, we show that the J-Calibration system is non-inferior and therefore is suitable for use in laboratory screening prior to deployment. Based on these advantages, the J-Calibration system will make a strong contribution to the deployment of healthy Argo fleets and to the maintenance of uniform data in the global ocean.
\end{abstract}

Keywords: CTD sensor, Sensor screening, SBE41, Simple calibration method, Water temperature control, Global Argo observation system

\section{Introduction}

Accurate data of uniform quality is critical to obtaining robust results in the Earth Sciences. However, this data can be very difficult to obtain in situations with a smaller signal-to-noise ratio when using spatially and temporally broad observation systems. For example, in physical

\footnotetext{
* Correspondence: hosodas@jamstec.go.jp

${ }^{1}$ Research Institute for Global Change, Japan Agency for Marine-Earth Science and Technology, 2-15 Natsushima-cho, Yokosuka, Kanagawa 237-0061, Japan

Full list of author information is available at the end of the article
}

oceanography, detection of the oceanic signals associated with long-term climate change is a key challenge as these tend to be more subtle and less specific than the signals which indicate shorter-term change (e.g., Meyers et al. 1982; White 1995). Especially in the middle depth of the ocean below $1000 \mathrm{~m}$, the amplitude of long-term changes in signals such as temperature and salinity is $1 /$ $100 \sim 1 / 1000$ th that of the upper layer. For example, it has been reported that the Antarctic Bottom Water, which is known as the lowest water mass of the global ocean circulation system, has warmed and freshened 
within the range of $0.01 \sim 0.001{ }^{\circ} \mathrm{C}$ or PSS-78 (e.g., Jacobs and Giulivi 2010; Purkey and Johnson 2010). Although this seems quite small, this variability associated with climate change signals is meaningful. To detect such a small perturbation, high-quality controlled sensors with high, consistent accuracy are critical. Therefore, many scientists recognize that sensor calibration prior to deployment is an absolute requirement in order to detect such small signals. Here, we introduce a new method of pre-deployment sensor calibration and demonstrate its importance in Argo float sensor calibration as part of the framework of the Argo program in the global ocean observation system.

The Argo program, which was started in 1999, aims to detect the small-amplitude climate signals associated with long-term climate change in the global ocean. The goal of the Argo observation system is to sustainably obtain uniform quality-controlled temperature and salinity data from the upper layer of the global ocean. To achieve this, autonomous observation drifting buoys, named Argo floats, are deployed every $3^{\circ}$ squared in the global ocean (Roemmich et al. 2001). All Argo floats are equipped with Conductivity Temperature and Depth Device (CTD) sensor devices. There are now over 3800 Argo floats deployed in collaboration with over 30 countries (Argo Science Team 1999).

Argo floats generally dive to a depth of $1000 \mathrm{~m}$ after deployment, and drift for 10 days. The floats then observe temperature, salinity, and pressure going up from a depth of $2000 \mathrm{~m}$ to the sea surface, continuously operating for 4-8years. This automated ocean observation makes it possible to collect a huge amount of data from the global ocean over a long period. The target accuracies of the CTD sensors on the Argo floats are set to $\pm 0.005^{\circ} \mathrm{C}$ for temperature, \pm 0.01 PSS-78 for salinity, and \pm 5 dbar for pressure, and these criteria must be maintained globally, both spatially and temporally. Once a float is deployed, direct confirmation of sensor accuracies is impossible, in contrast to a shipboard CTD observation, which can be compared by post-calibration in a laboratory. Therefore, when the Argo program began, it was decided by the Argo data management team that a data flow and quality control method would be established in order to maintain high-quality uniform data. This method involves real-time quality control (rQC), which is analyzed by the Argo data assembly centers (DAC) within $24 \mathrm{~h}$ after measurement, as well as a delayed-mode quality control (dQC), which is carried out for research purposes by the principal investigator (PI) within 1 year of the rQC. Historical shipboard CTD data and other Argo float data are used to detect sensitive climate change signals (Argo Data
Management Team 2002, 2012). Then, all Argo float data is made available online at the Global Data Assembly Center (GDAC). Based on this qualitycontrolled data, small detailed signals in the interior ocean indicating climate and ocean environmental changes have been detected successfully (e.g., Riser et al. 2016).

The CTD sensor equipped on almost all Argo floats is currently the SBE41, manufactured by Sea Bird Scientific (https://www.seabird.com/sbe-41-argo-ctd/product?id=54627907875). The pre-production SBE41 CTD unit was installed on a University of Washington Webb/APEX float in 1997 and was deployed in the North Atlantic Ocean and operated successfully for 3 years. The first CTD on a profiling float was added to an autonomous Lagrangian circulation explorer (ALACE) float (Davis et al. 1992) by a group from the Scripps Institute of Oceanography (SIO, USA) around 1994. However, this was not a SBE41 but an inductive CTD sensor manufactured by Falumouth Scientific, Inc. (FSI CTD) and performed poorly with large salinity biases and temporal drift. Although a number of FSI CTD units were built and deployed over a few years, their use was discontinued due to poor results. Based on a review of the stability of the SBE41 CTD sensor, the sensor unit used on Argo floats is now primarily mounted with verifications of target accuracy and long-term stability (Oka 2005; Johnson et al. 2007). The SBE41 sensor units are equipped with temperature, salinity, and pressure sensors, which are the fundamental physical parameters in the ocean. Thermistor and piezoelectric sensors are used for temperature and pressure measurements, respectively. The conductivity sensor is used for salinity and measures seawater conductivity between electrodes inside a glass tube. The measured conductivity is transformed into salinity as a function of temperature and pressure, which are obtained from the equipped temperature and pressure sensors (UNESCO 1978). The specifications of the SBE41 CTD sensor unit are shown in Table 1.

We have conducted operating tests on all delivered Argo floats and screened sensor accuracies for many SBE41 sensors in the laboratory before deployment (Yokota et al. 2007). The screening system for the SBE41 temperature and salinity sensor is available and operated at JAMSTEC in a similar fashion to that of Sea Bird Scientific, the manufacturer of SBE41 (here, we refer to the calibration in JAMSTEC as "SBE-Calibration"). Prior to shipping SBE41 to users, optimal parameters are determined for each sensor based on the results of the manufacturer's calibration and are indicated in the calibration certifications. Thus, it is possible to check and screen 
Table 1 Feature and specification of SBE41 CTD sensor unit manufactured by Sea Bird Scientific

\begin{tabular}{llll}
\hline Sensor & Range & Accuracy & Stability \\
\hline Temperature & $-2 \sim 35^{\circ} \mathrm{C}$ & $\pm 0.002^{\circ} \mathrm{C}$ & $0.0002^{\circ} \mathrm{C} /$ year \\
Conductivity & $2 \sim 42$ (equivalent salinity) & \pm 0.005 (equivalent salinity) & $0.001 /$ year (equivalent salinity) \\
Pressure & $0 \sim 2500 \mathrm{dbar}$ & $\pm 2.4 \mathrm{dbar}$ & $0.8 \mathrm{dbar} /$ year \\
\hline
\end{tabular}

sensor accuracies by conducting SBE-Calibration in JAMSTEC prior to float deployment through a comparison with the calibration result of the manufacturer. The University of Washington also uses a screening system for SBE41 sensors similar to the SBE-Calibration system at JAMSTEC, and reported that the system is stable and accurate (Riser et al. 2008). Since 2001, we have found over 50 faulty sensors in SBE41 prior to deployment through screening over 1000 sensors calibrated by SBE-Calibration. Furthermore, systematic faults in sensors have been found, which was raised as an international problem in the Argo community (e.g., Atlantic Ocean cooling by data bias; Lyman et al. 2006; Willis et al. 2008, Systematic SBE41 salty drift; Argo Steering Team 2018, 2019). Therefore, it is recognized in the Argo community that screening for faulty sensors prior to deployment is largely effective in reducing the issues of deployed floats with bad sensors (King et al. 2017). However, such screening of sensors calibrated by SBE-Calibration or a similar method tends to be complex and requires specialized skills and equipment, which makes it difficult to screen sensors operationally at a user level. In addition, user removal of the CTD sensor unit from the float body can create warranty issues.

Recent difficulties with hardware and software on Argo floats have occurred due to increased price competition among manufacturers. For float users, although a low-cost float is welcome, encountering difficulties which are results of cost-cutting results in delayed float deployment and poor data accuracy. Therefore, user monitoring float performance prior to deployment to avoid deployment of floats with faulty sensors is absolutely required.

Under these circumstances, we had developed a new method of SBE41 CTD sensor screening to be performed in a laboratory which does not require the removal of the CTD sensor unit from the float body. We have validated the accuracy of this system and call the system "J-Calibration." The goals of the development of this system were (1) to achieve a CTD sensor screening system similar in accuracy to that of SBE-Calibration in JAMSTEC and (2) to be able to operate efficiently and without the need for specialized technicians. Finally, we desire to deliver this system to the other agencies and institutes in order to contribute to the achievement of uniform highquality data for the international Argo program and observation system.

\section{Methods/Experimental}

\section{$\mathrm{J}$-Calibration system and its advantages}

J-Calibration is an efficient calibration method of the SBE41 CTD sensor unit which does not require the separation of the sensor unit from the float body, while maintaining an accuracy similar to that of SBECalibration. Since the sensor unit of SBE41 is not separated, the temperature and conductivity sensors of SBE41 can be calibrated by instilling seawater directly into the sensor unit. In J-Calibration, measurement of temperature and conductivity of the seawater is carried out using standard sensors of SBE3 and 4 at the same time to validate accuracy. This validation procedure with standard sensors enables us to improve reliability and to maintain the accuracy of SBECalibration.

The J-Calibration system is shown in Figs. 1 and 2, and the components of J-Calibration are listed in Table 2. The J-Calibration system consists of a seawater tank (10l), standard temperature and salinity sensors, SBE41 sensors (up to 3 sensor units), and a water pump, sequentially connected with water tubes. Each tube with sensors is trimmed to the same length. The system is controlled by laptop computers, communicating with each float body. Although SBE3 and 4 standard sensors are manufactured by SBEsharing with SBE-Calibration, other items were purchased at affordable prices.

The artificial seawater is a $\mathrm{NaCl}$ solution seawater at $35 \pm 0.1$ PSS-78 and is prepared by degassing and minimizing the difference with room temperature in advance. The seawater flows to three SBE41 sensors and to SBE3 and 4 standard sensors separately and constantly via a pump through the tubes. The length of the tubes between the sensors and the seawater tank is consistent at $1.8 \mathrm{~m}$ in order to maintain a uniform exposure to the heat in the environment. In order to avoid excess water pressure and potential error, the flow of seawater is consistent at $200 \mathrm{ml} / \mathrm{min}$ for each tube. Calibration is started 3-5 min after starting water circulation and after ensuring 


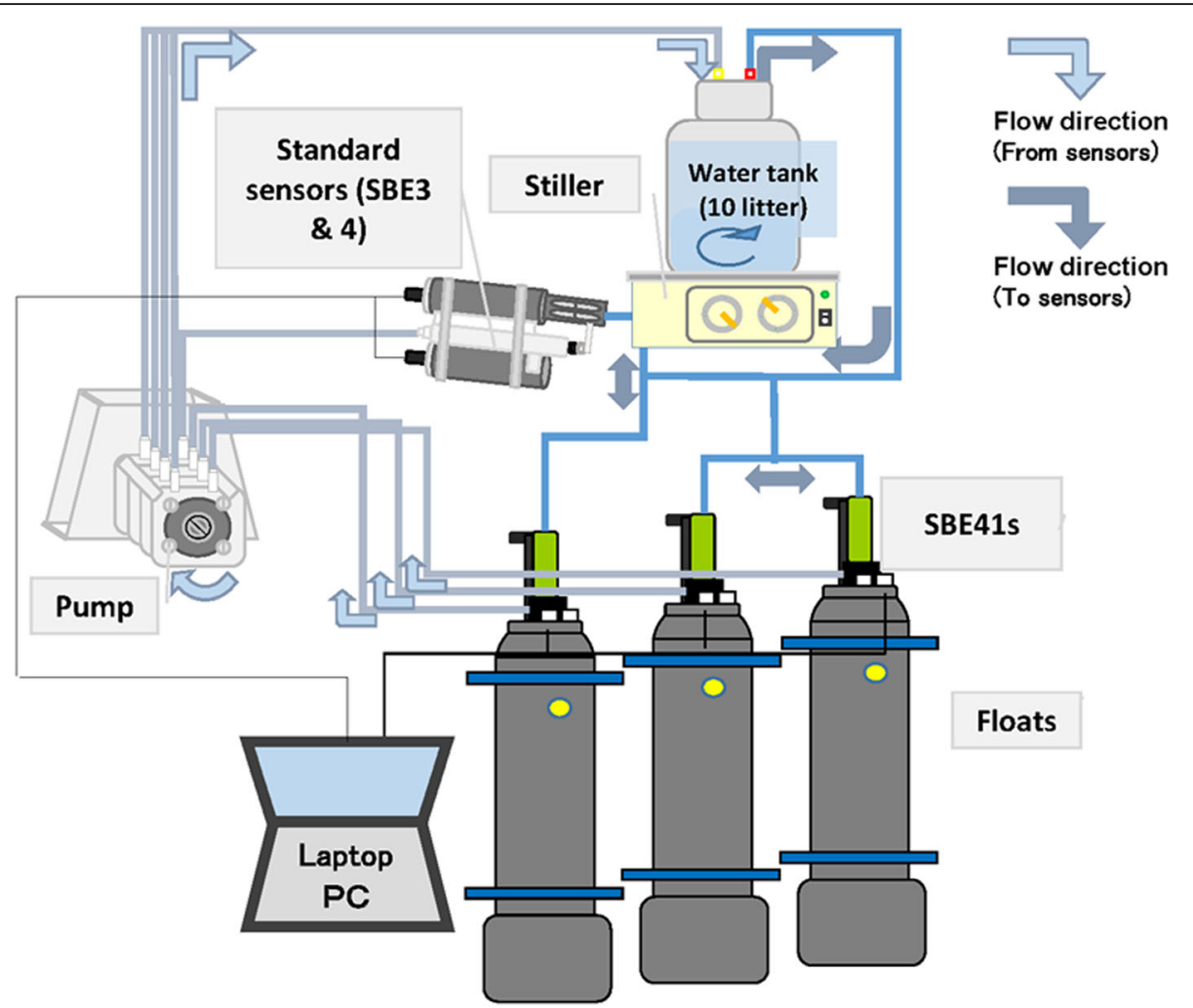

Fig. 1 Schematic figure of the J-Calibration system. The system consists of a small water tank (10 I), a stiller for mixing seawater, SBE3 and 4 standard sensors, and a water pump (see Table 4). Three floats with SBE41 and standard sensors (SBE3 and 4) are controlled by a laptop computer. The artificial seawater flows through water tubes

temperature stability (variability of water temperature within $\pm 0.01^{\circ} \mathrm{C}$ ). The period of one measurement is $5 \mathrm{~min}$, but the time does depend on the season and the room temperature of the environment.
Since conductivity is a function of water temperature, it is generally difficult to calibrate salinity sensors accurately as it is largely influenced by the temperature of the environment. Therefore, it is

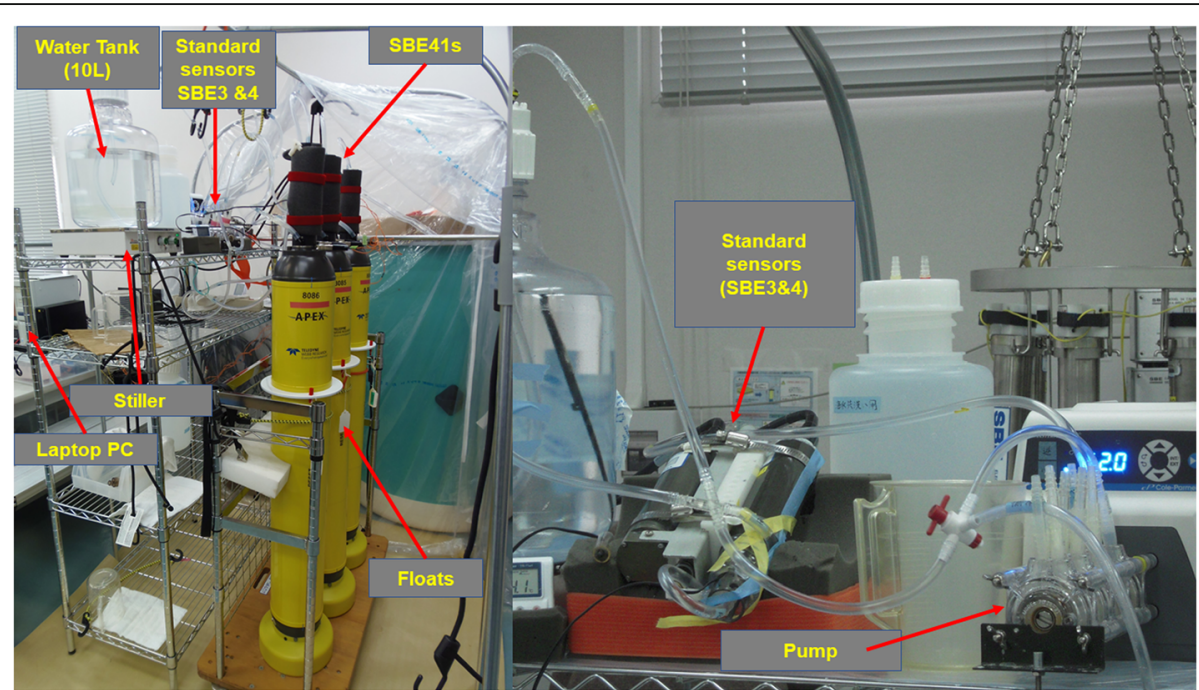

Fig. 2 (Left) The J-Calibration system in an open Vinyl greenhouse. Using a steel rack, a required space is minimized (within $1 \mathrm{~m}^{2}$ ). (Right) A detailed photo of the pump and SBE3 and 4 
Table 2 List of items used in J-Calibration (see Figs. 1 and 2)

\begin{tabular}{|c|c|}
\hline & Items \\
\hline 1 & Water tank (10 I) \\
\hline 2 & $\begin{array}{l}\text { Water tube (length is } 1.8 \mathrm{~m} \text { every part, connecting among water } \\
\text { tank, pump, and sensors) }\end{array}$ \\
\hline 3 & $\begin{array}{l}\text { Pump for seawater (flow speed sets } 0.2 \mathrm{l} / \mathrm{min} \text { which is the same } \\
\text { as actual flow speed of SBE41 sensor pump) }\end{array}$ \\
\hline 4 & Vinyl house $(1.7 \mathrm{~m}$ width $\times 1.7 \mathrm{~m}$ length $\times 2.0 \mathrm{~m}$ height $)$ \\
\hline 5 & Laptop computer (connecting to SBE41s and SBE3 and 4) \\
\hline 6 & Cooling packs $(15 \mathrm{~cm} \times 10 \mathrm{~cm}, 2$ or 4 packs) \\
\hline 7 & Rack ( $1.0 \mathrm{~m}$ width $\times 0.5 \mathrm{~m}$ length $\times 1.2 \mathrm{~m}$ height $)$ \\
\hline 8 & Stiller (2 cycles/s) \\
\hline 9 & Timer (measurement every second) \\
\hline $10 *$ & $\begin{array}{l}\text { SBE3 and } 4 \text { (manufactured by SBE, sharing with SBE-Calibration } \\
\text { system) }\end{array}$ \\
\hline
\end{tabular}

Note: * mark at number column means an item from SBE-Calibration system

important to maintain a uniform seawater temperature. However, in contrast with SBECalibration, maintenance of the water temperature and conductivity in the J-Calibration system is not easy, as the sensors are not fully submerged in seawater, and the water insulating/cooling controller is not used as it is in SBE-Calibration. Therefore, we need to manage J-Calibration carefully (see items in
Table 2). A detailed explanation and evaluation are documented later.

\section{Differences between the SBE-Calibration system and J- Calibration}

The SBE-Calibration system is shown in Figs. 3 and 4 , and the differences between the J-Calibration and SBE-Calibration systems are summarized in Table 3. SBE-Calibration, which was previously operated as a basic calibration system in the laboratory of JAMSTEC, compares measurements of seawater in SBE41s with SBE3 and 4 standard sensors whose accuracies are already validated by the manufacturer of SBE. The SBE-Calibration system consists of a calibration bath, a water insulating/cooling controller, a deck unit controller, and a bath controller (using a laptop computer for the bath controller). The deck unit controls SBE41 sensors and the SBE3 and 4 standard sensors to send control commands, and strictly maintains water temperature. The SBE-Calibration system evaluates several SBE41s (up to 5 units) to compare with the output of the standard sensors (SBE3 and 4; accuracies are $\pm 0.001{ }^{\circ} \mathrm{C}$ for temperature and \pm 0.001 PSS-78 for salinity) by measuring artificial seawater $(230 \mathrm{l})$ in a water bath. The artificial seawater is a $\mathrm{NaCl}$ solution and its salinity concentration is set at 35.0 PSS-78, which is the same as in J-Calibration.

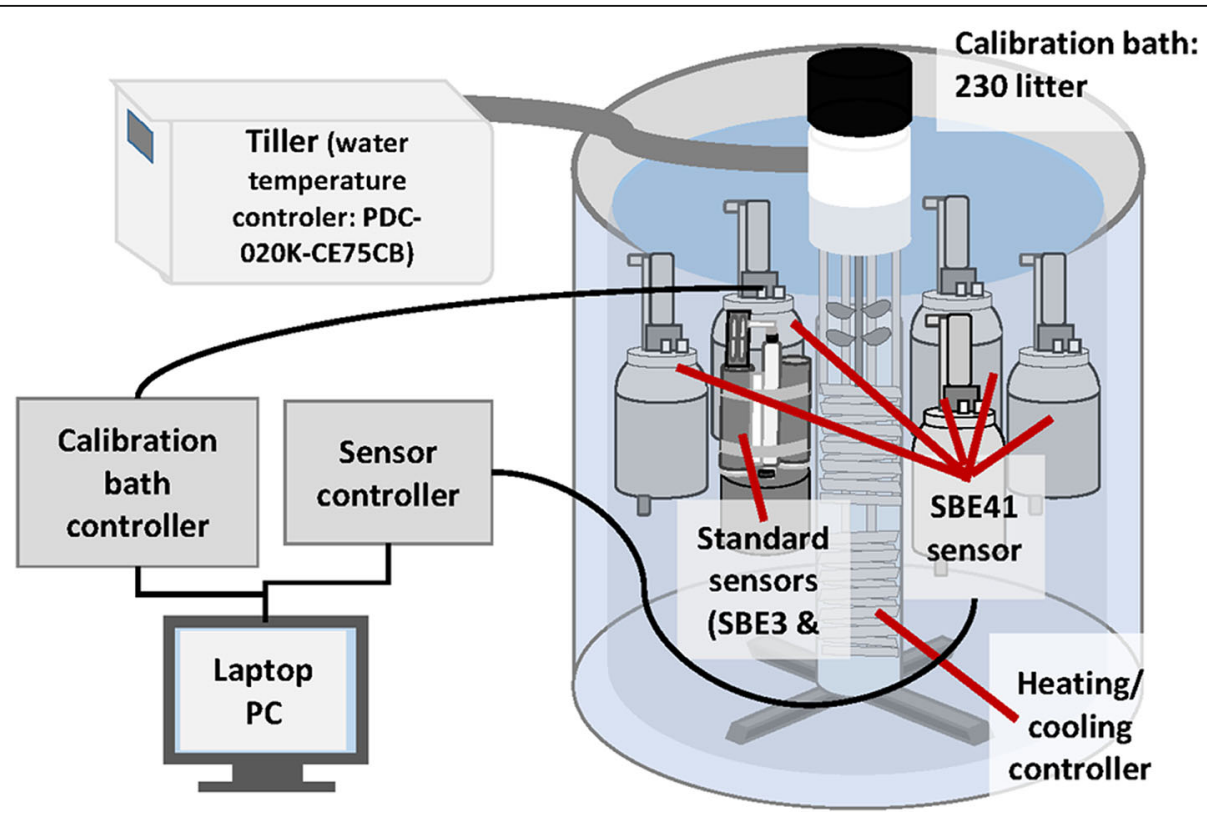

Fig. 3 Schematics of the SBE-Calibration system. The system consists of a large water tank (230 I), an insulating/cooling controller (tiller), a calibration bus controller, a sensor controller for SBE3 and 4, and a laptop computer. The laptop computer can send a command to sensors via the controllers and receive signals, and vice versa. The SBE41 sensors and standard sensors (SBE3 and 4) are placed into the tank flowing into the artificial seawater in the bath. Temperature in the tank is maintained with a heating/cooling controller and a water temperature controller surrounded the calibration bath by adiabatic materials 


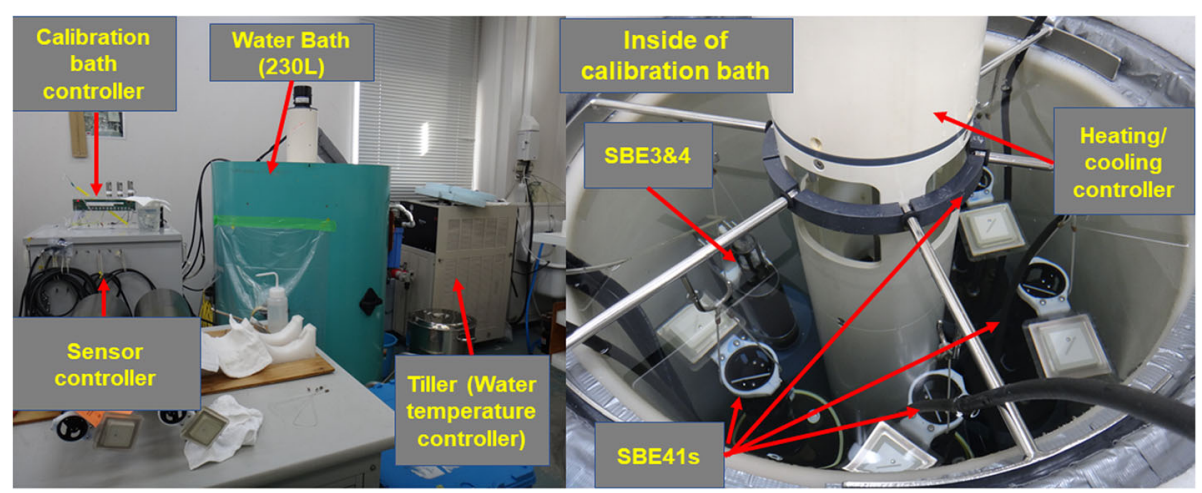

Fig. 4 (Left) Overall SBE-Calibration system. The system is separated into three components; two controllers, and a calibration bath. (Right) A detailed photo inside of the calibration bath for the SBE-Calibration system. The SBE41 sensor units (4 of 5 sensor units are shown in this photo) and SBE3 and 4 of the standard sensors were placed into the bath of artificial seawater. The artificial seawater is maintained at a uniform temperature and monitored by a water temperature controller and heating/cooling controllers

Although the sensors are submerged in the artificial seawater bath using adiabatic materials in SBECalibration, the water temperature still varies with heating from the stiller, sensors, and other items. To maintain a stable water temperature, a water insulating/cooling controller is used.

In the calibration of SBE41 sensors by the manufacturer, measurements for the calibration are conducted at 7 conductivity points varying the temperature under the same salinity, which is the same as that of SBE-Calibration. Regarding SBECalibration at JAMSTEC, if the differences in temperature and conductivity are larger than the criteria that satisfy the Argo accuracies, we check the sensors and occasionally change their coefficients or return the device to the manufacturer to repair the sensors. This screening before deployment is effective because the sensor error can occur accidentally either before delivery from the manufacturer or through a failure of calibration during the sensor manufacturing process. At this time, we have calibrated over 1000 SBE41 sensors and have successfully used SBE-Calibration to screen faulty SBE41 sensors prior to deployment (Yokota et al. 2007).

However, since the SBE-Calibration system is expensive to operate in a general laboratory and requires a great deal of time from specialized technicians, it is challenging to implement the entire system. For this reason, we decided to develop a new, efficient, and simple calibration method with the goal of a shorter procedure time while still maintaining an accuracy similar to that of SBE-Calibration.

\section{Method of maintaining water temperature in J-Calibration} Unlike in SBE-Calibration, it is not necessary to set a fixed water temperature in J-Calibration, as JCalibration carries out validation through a comparison of measurements between standard sensors (SBE3 and 4) and a calibrated sensor (SBE41). However, the temperature and salinity of the seawater in JCalibration must be maintained as much as possible at every calibration in order to achieve a higher

Table 3 Differences of operational method between J-Calibration and SBE-Calibration

\begin{tabular}{lll}
\hline & J-Calibration & SBE-Calibration \\
\hline Artificial seawater & Flowing directly from the tank to sensors through tubes & Filling water in a big tank, put sensors into filling water. \\
$\begin{array}{l}\text { Amount of seawater per } \\
\text { one experiment }\end{array}$ & $10 \mathrm{~L}$ & $230 \mathrm{~L}$ \\
$\begin{array}{l}\text { Maintaining seawater } \\
\text { temperature }\end{array}$ & $\begin{array}{l}\text { Spot insulation of sensors and a part of tubes with } \\
\text { insulating material and housing. }\end{array}$ & $\begin{array}{l}\text { Tank surrounded by adiabatic material, controlling water } \\
\text { Removing CTD unit }\end{array}$ \\
Controlling system & Not necessary. & Necessary with special skills. \\
& Sending command to sensors and standard sensor by & Using a special computer unit manufactured by SBE. \\
\hline
\end{tabular}


precision. To achieve stable water temperature during experiments, the temperature environment of the water flow system must be carefully maintained, especially since the conductivity (salinity) sensor is largely influenced by both room temperature and water temperature. For example, as the length of the tubes with J-Calibration is longer than with SBECalibration, there tend to be many points of potential heat penetration through sensors, connectors, and tubes. The calibration accuracy tends to be worse if the water temperature is not controlled well.

To minimize the influence of heating and cooling of seawater on the J-Calibration system, we utilized adiabatic materials for each SBE41 CTD sensor unit (Fig. 5a, b). The adiabatic materials serve to increase or decrease temperatures by heating or cooling from the outside.

Additionally, the SBE3 and 4 standard sensors tend to radiate heat during experiments because their electric power consumption is larger than SBE41. This can cause a large change in water temperatures. In the case of SBE-Calibration, this increase in water temperature by the standard sensor unit is minimized because a large amount of water used (230 l) has a larger heat capacity and water temperature is controlled through the water insulating/cooling controller. To avoid temperature

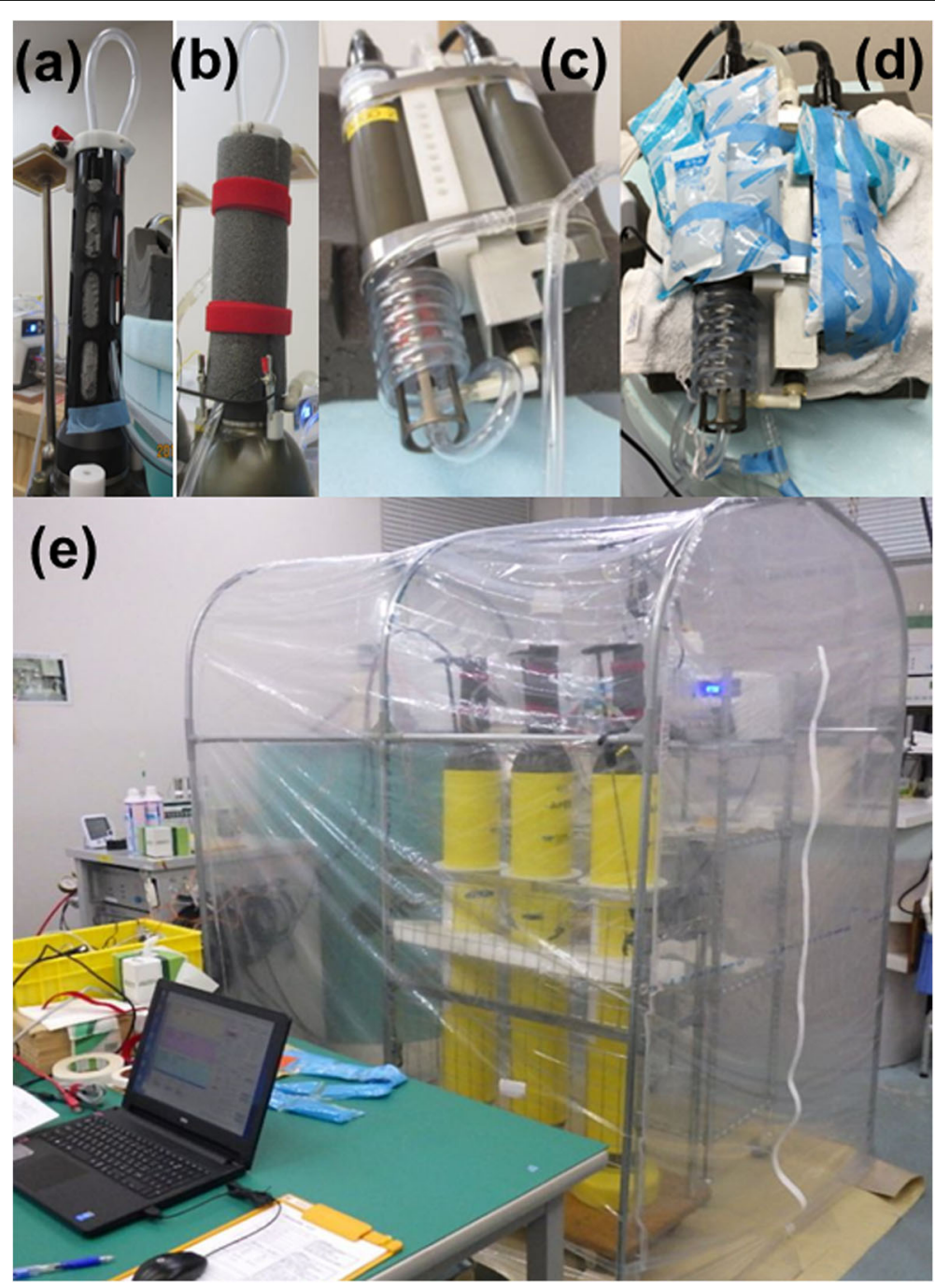

Fig. 5 a SBE41 sensor unit. Conductivity and temperature sensors are surrounded by a black plastic cover. In J-Calibration, inside of the cover, a cushioning material wraps around the sensors as an adiabatic material. $\mathbf{b}$ In addition to $\mathbf{a}$, another adiabatic material covers the outside of the plastic cover. This double covering material effectively maintains the stability of temperature measurements using SBE41 sensors. c SBE3 and 4 standard sensors. A tube connecting the tank to the standard sensor is wound around the sensors. $\mathbf{d}$ In addition to $\mathbf{c}$, cooling packs are attached to SBE3 and 4. The cooling packs can be easily obtained from any supermarket in Japan. e Vinyl greenhouse covering floats 
increase in J-Calibration, we introduced two methods. One is to install tubing around the SBE3 and 4 standard sensors and cool them by pumping water into the tube wound around the sensors (Fig. 5c). The effect is to warm up the water and cool down the sensors themselves. Another method is to use cooling packs around SBE3 and 4 standard sensors to decrease water temperature and therefore that of the sensors (Fig. 5d). The number of packs required depends on the season, for example, two packs are required for each sensor in summer, while four packs are required in the winter.

It is critical to control the temperature of the air in order to ensure a stable water temperature. During the screening procedure, we kept an air conditioner at $22{ }^{\circ} \mathrm{C}$ just before starting the experiments, and then stopped it to avoid disturbing the air during actual measurements. Further, we used a vinyl greenhouse to maintain a stable air temperature. When the JCalibration system is prepared with a water tank, the greenhouse was placed on the entire system to cover the entire experimental setup (Fig. 5e). The sheet of greenhouse was subsequently opened for an hour to adjust to room temperature. Here, we put a small table for a workspace inside of the greenhouse, the height of which was $10-30 \mathrm{~cm}$ below that of the SBE41 sensors, for our convenience. When the experiment was started, the sheet of the greenhouse was closed.

Based on the above factors which affect water temperature, we carried out four experiments to evaluate methods of maintaining room and water temperature involving (1) turning off the airconditioner, (2) insulating/cooling the SBE41, SBE3,
Table 4 Water temperature control experiments for J-

Calibration

\begin{tabular}{llllll}
\hline Experiments & (1) & (2) & (3) & (4) \\
\hline Off air conditioner & & & 0 & $\circ$ & 0 \\
Insulating/cooling packs & & & 0 & $\circ$ \\
Vinyl greenhouse & & & & & \\
SBE41-Ref. (20 min avg.) & $\Delta \mathrm{T}\left(\times 10^{-3}{ }^{\circ} \mathrm{C}\right)$ & 26.2 & -3.9 & -0.6 & 0.3 \\
& $\Delta \mathrm{C}\left(\times 10^{-3} \mathrm{~S} \mathrm{~m}^{-1}\right)$ & 1.3 & -1.1 & -0.6 & 0.1 \\
& $\Delta \mathrm{S}\left(\times 10^{-3} \mathrm{PSS}-78\right)$ & -10.9 & -5.5 & -3.8 & 0.7
\end{tabular}

$\Delta \mathrm{T}, \Delta \mathrm{C}$, and $\Delta \mathrm{C}$ mean difference between SBE41 and standard sensor (float $\mathrm{S} /$ $\mathrm{N}$ 914), being measured and averaged for $20 \mathrm{~min}$

and 4 standard sensors, and (3) covering with the vinyl greenhouse. These experiments were used to carry out our evaluation of J-Calibration by estimating the differences between the SBE41 and standard sensors (Table 4).

In comparing differences in air temperature when utilizing the air conditioner, we found that smaller differences in amplitudes $(1 / 7$ and 1/2) for temperature and salinity, respectively, were achieved ((2) in Table 4). This indicates that the mixing of air in the room by the air conditioner tends to create turbulence, which in turn leads to differences in temperatures that are likely to be large ((1) in Table 4). Because of the large influence of the air conditioner on the stability of the calibration system, the air conditioner must be stopped during the experiments. It also means that the time for each experiment must be shortened as much as possible to avoid gradual temperature drift.

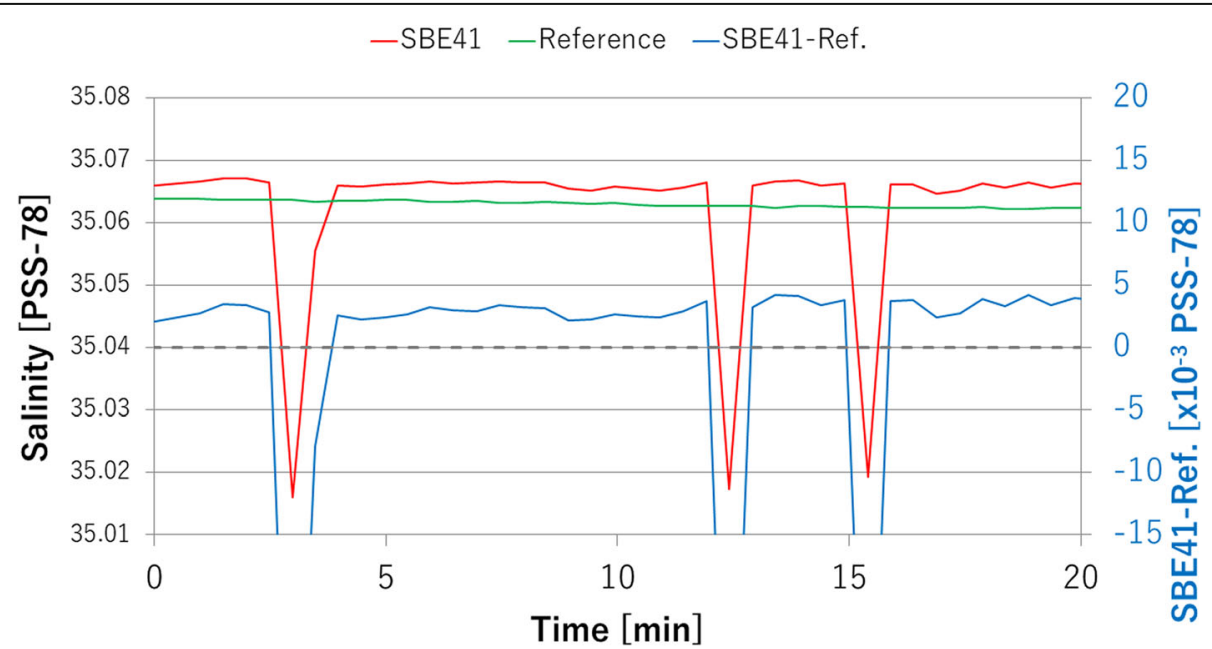

Fig. 6 Salinity of experiments contaminated with bubbles in the water. Salinity measured by the SBE41 sensor (red line), SBE3 and 4 standard sensors (green line), and the difference between the two (blue line). Salinity is measured as PSS-78 except for the difference of salinity which is $\times 10^{-3}$ PSS-78 
Next, adiabatic materials and cooling packs are attached at temperature and conductivity sensors on SBE41 and to the standard sensors, to avoid increasing water temperature through heating from the sensors themselves and cooling by temperature differences between the air and water temperature ((3) in Table 4). Based on these materials and packs, the differences tended to be stable, decreasing them by $1 / 3$ rd to $1 / 5$ th as shown by case (2) in Table 4 . Further, covering the J-Calibration system makes it

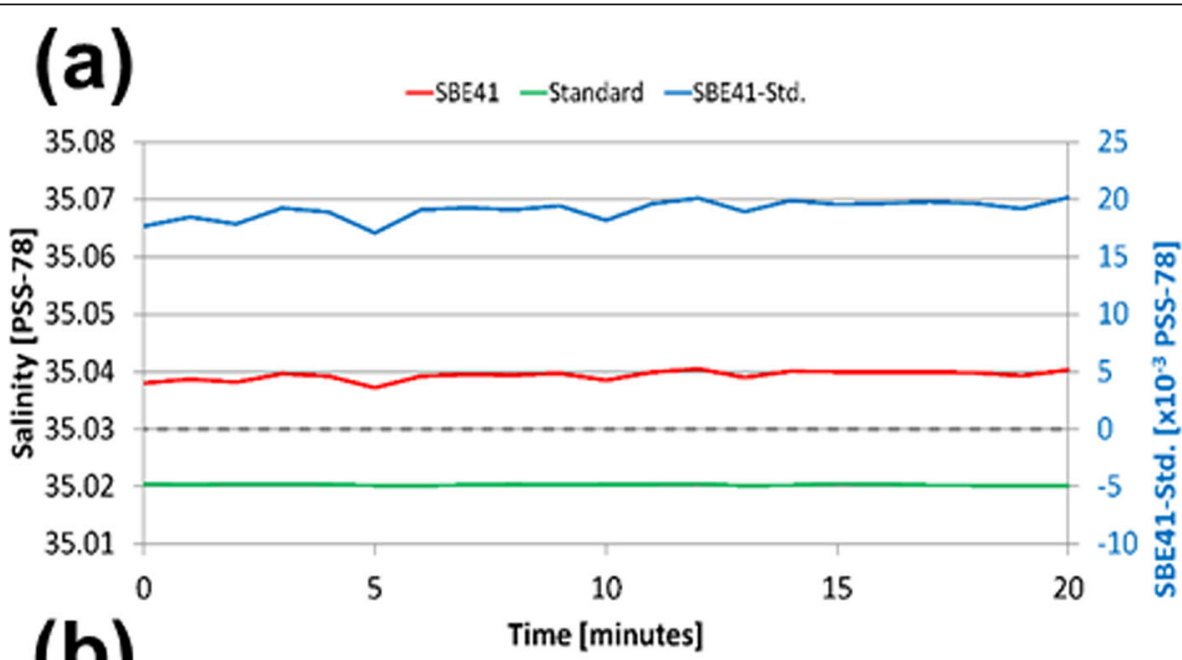

-SBE41 -Standard -SBE41-Std.
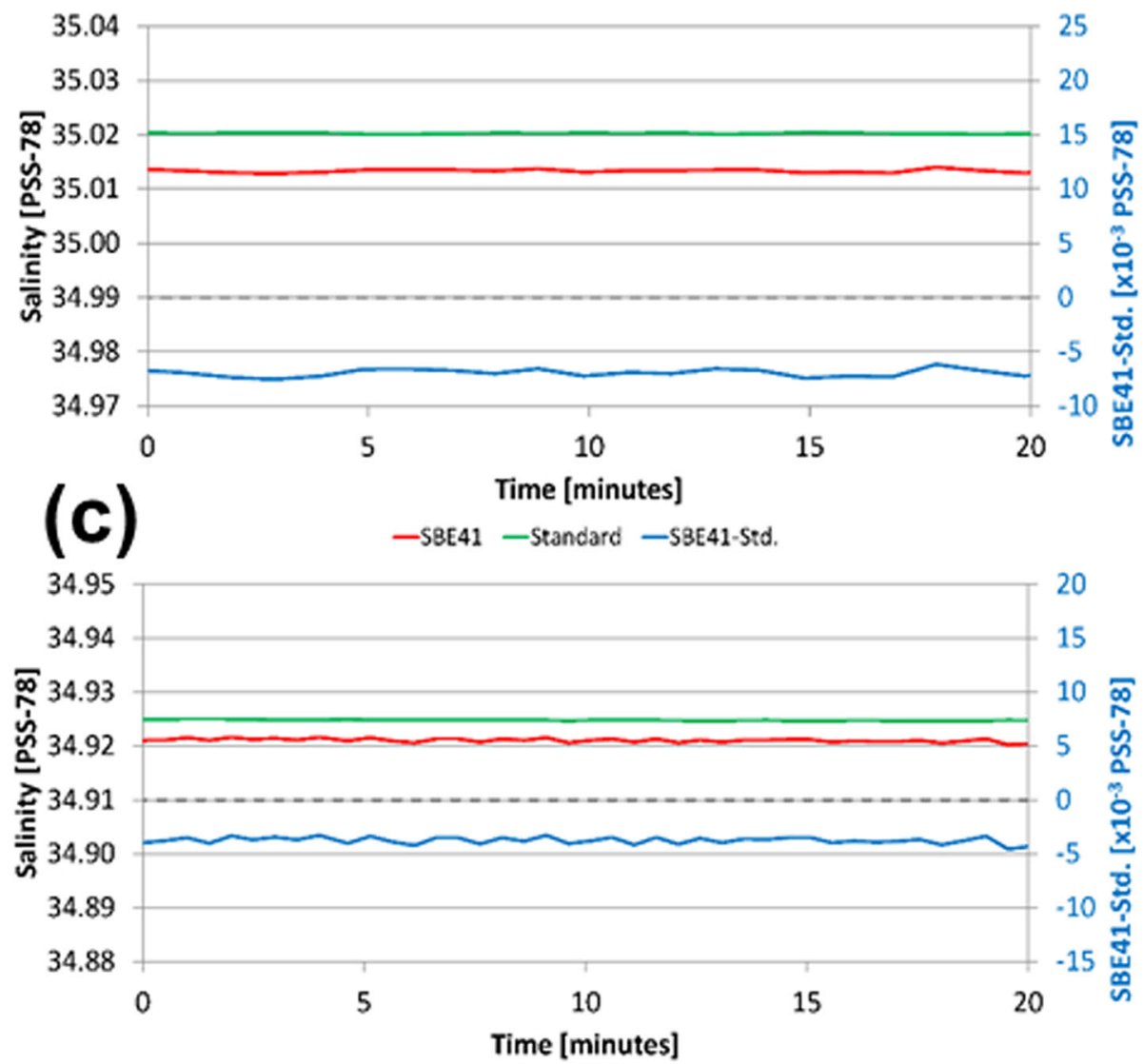

Fig. 7 The same as Fig. 6 except for salinity of calibration experiments without adiabatic material (a), with adiabatic material (b), and with adiabatic material and cooling packs (c) 
possible to minimize water temperature variability within $\pm 1{ }^{\circ} \mathrm{C}$ to avoid the increased turbulence outside of the vinyl greenhouse ((4) in Table 4).

We then carried out several experiments to determine if undertaking the measures described above was effective or not. Figure 6 depicts an example of an experiment introducing contaminating bubbles into artificial seawater, which occurs when the degassing procedure is not used. During a 20-min experiment, a few negative salinity spikes appear caused by passing

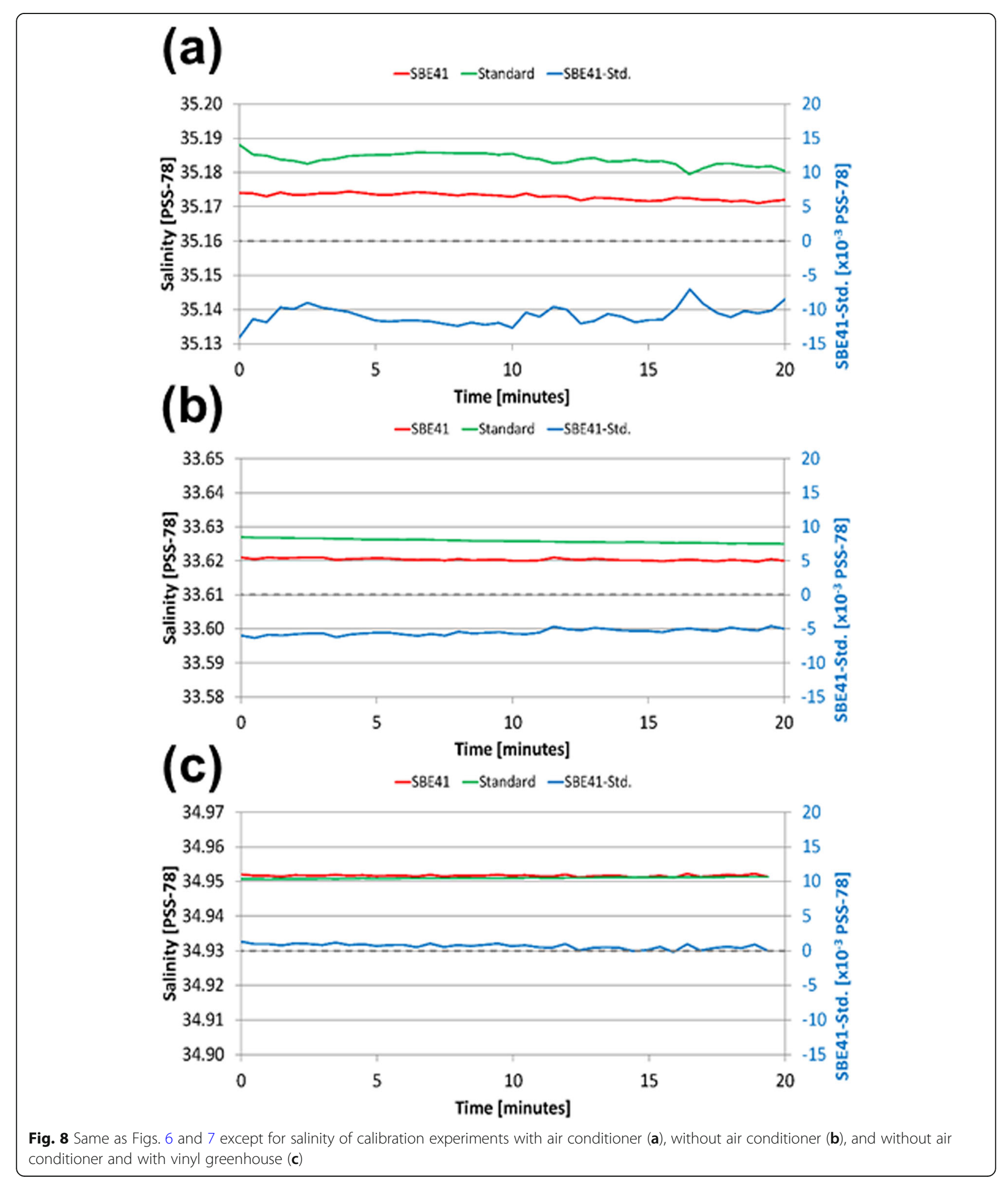


bubbles through the glass tube containing the electrodes of the conductivity sensor. Figure 7 shows the salinity change of SBE41 and the standard sensor and their difference with adiabatic materials and cooling packs. Under the conditions of stable air conditioning using adiabatic materials and removing the bubbles, the difference of salinity becomes smaller than that without the materials and packs. Figure 8 shows the effect of salinity change by maintaining a room temperature environment and the effectiveness of stopping the air conditioner (middle) and covering a vinyl greenhouse. Under the condition that adiabatic materials and cooling packs are attached, salinity becomes more stable if the air conditioner is turned off. Furthermore, the vinyl greenhouse is quite effective in that the salinity difference between the SBE41 and the standard sensor is nearly 0 .

\section{Water temperature setting in J-Calibration: best choice to minimize missing screening}

In SBE-Calibration, SBE41 sensors are calibrated using artificial seawater, varying the conductivity with temperature at 7 points. Because conductivity is mainly a function of temperature, changing the temperature is an alternative way to calibrate the salinity sensors. However, since changing the temperature at 7 points is very time consuming, the number of screenings of SBE41 sensors that can be completed is limited. If J-Calibration is conducted by varying temperatures at 7 points, it takes even more time than SBE-Calibration, even though the size of the tank is smaller in J-Calibration, as the water temperature needs to be homogenous.

Therefore, we must find the most appropriate temperature to calibrate SBE41 sensors to minimize missing screening. Here, we evaluate the temperature based on the results of experiments with SBECalibration, which were conducted from 2011 to 2016. The number of SBE41 sensor units with faults from SBE-Calibration at JAMSTEC was 20, and these were sent to the manufacturer to check and recalibrate whether the sensors were truly faulty or not. Table 5 summarizes the number and the rate of SBE41 CTDs that were judged as faulty in SBECalibration at JAMSTEC but were healthy in the calibration by the SBE manufacturer. Essentially, SBE-
Calibration is conducted repeatedly for each SBE41 sensor unit when it is judged as a faulty sensor during its first SBE-Calibration. In total, we completed 65 experiments of SBE-Calibration for 20 SBE41 CTD units. The number of misjudged CTD units is clearly minimal at $5.2 \mathrm{~S} \mathrm{~m}^{-1}$ (equivalent to $24{ }^{\circ} \mathrm{C}$ for 35 PSS78 ), which is a rate of less than $1.5 \%$. Based on this result, we used one temperature point $\left(24^{\circ} \mathrm{C}\right)$ to screen faulty SBE41 sensors in J-Calibration with the goal of finding faulty sensors using a short experiment time.

As mentioned in the previous subsection, the important point of this J-Calibration system is not only to precisely control water and air temperature but to also minimize the variability in differences between the calibrated sensor (SBE41) and the standard sensors (SBE3 and 4). Therefore, it is crucial for JCalibration to keep a uniform temperature during an experiment for approximately $10 \mathrm{~min}$. Here, the target precision of seawater temperature is $24 \pm 0.5^{\circ} \mathrm{C}$, which is empirically responsible for a stable J-Calibration result. Figure $9 \mathrm{a}, \mathrm{b}$ shows the stability of temperature and salinity during every experiment of J-Calibration. The result shows that the seawater temperature and salinity are almost unchanged and uniform within \pm $0.001{ }^{\circ} \mathrm{C}$ and \pm 0.001 PSS-78, respectively, during the first $10 \mathrm{~min}$ of the calibration.

\section{Use of artificial seawater for J-Calibration}

The artificial seawater for J-Calibration is degassed in advance for $24 \mathrm{~h}$ to be stable during calibrations. Before starting screening, pure water is placed into a bucket $(40 \mathrm{l})$ with salt $(1.4 \mathrm{~kg} \mathrm{NaCl})$ and mixed at $300 \mathrm{rpm}$ by a stirrer. After $20 \mathrm{~min}$, when the water fully dissolves the salt, the rotating speed of the stirrer is changed to $100 \mathrm{rpm}$, and the standard sensors are put into the bath, conditioning salinity to $35 \pm$ 0.1 PSS-78. To degas the conditioning artificial seawater, the water heats and is kept at $33^{\circ} \mathrm{C}$ for some time, then is naturally cooled overnight to stabilize at room temperature. Before screening, the water stirrers are again placed in the bucket to achieve a uniform salt concentration. Then, we expose the water to a vacuum to help remove bubbles $(0.04$ $\mathrm{MPa}$ ), and re-stirring of the water is conducted in a smaller water tank (10l) to degas it completely. The

Table 5 Missing screening and its rate of conductivity sensor error at 7 temperature points on SBE-Calibration at JAMSTEC

\begin{tabular}{llllllll}
\hline Conductivity $\left(\mathrm{S} \mathrm{m}^{-1}\right)$ & $3.0\left(1.0^{\circ} \mathrm{C}\right)$ & $3.3\left(4.5^{\circ} \mathrm{C}\right)$ & $4.2\left(15.0^{\circ} \mathrm{C}\right)$ & $4.6\left(18.5^{\circ} \mathrm{C}\right)$ & $5.2\left(24.0^{\circ} \mathrm{C}\right)$ & $5.7\left(29.0^{\circ} \mathrm{C}\right)$ & $6.0\left(32.5^{\circ} \mathrm{C}\right)$ \\
\hline No. of inconsistency & 20 & 11 & 5 & 3 & 1 & 3 & 22 \\
Rate of inconsistency (\%) & 30.8 & 16.9 & 7.7 & 4.6 & 1.5 & 4.6 & 33.9 \\
\hline
\end{tabular}




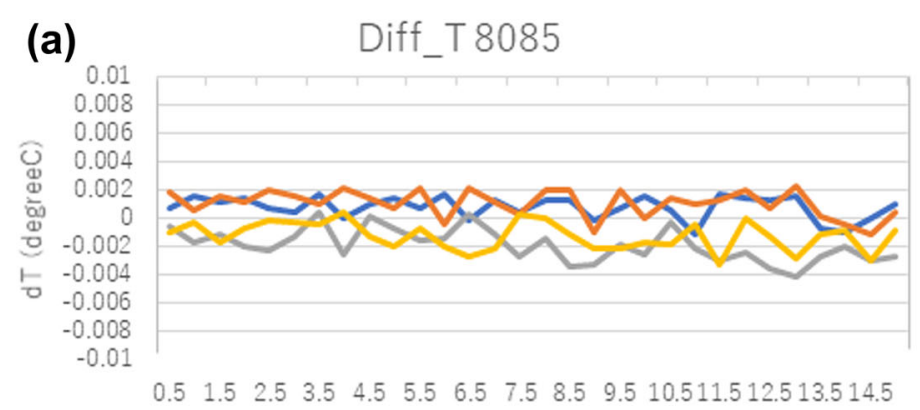

-Ex1 Ex2—Ex3—Ex4 Time (minutes)

Diff_S 8085

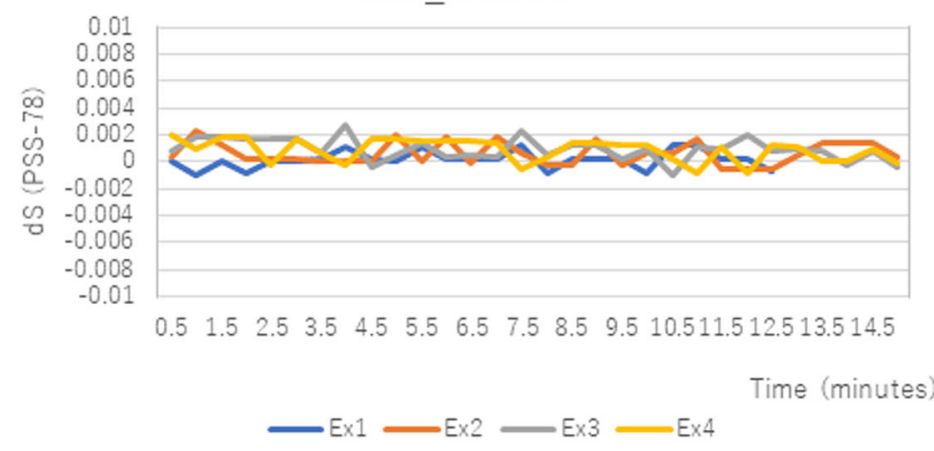

(b)

Diff_TF0584

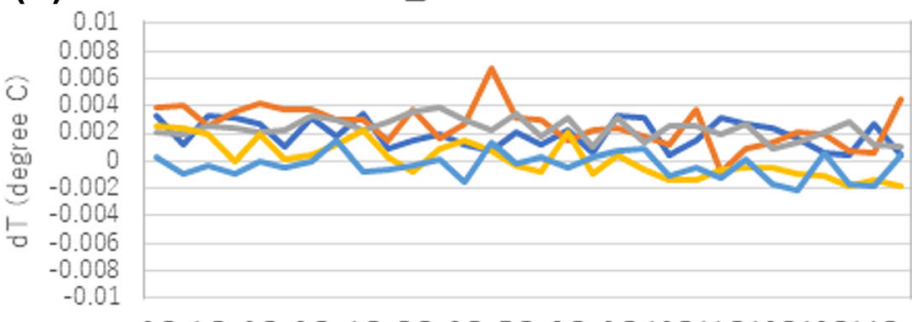

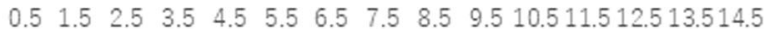

Time (minutes)

Ex1 Ex $E \times 2 — E \times 3-E \times 4-E \times 5$

Diff_S F0584

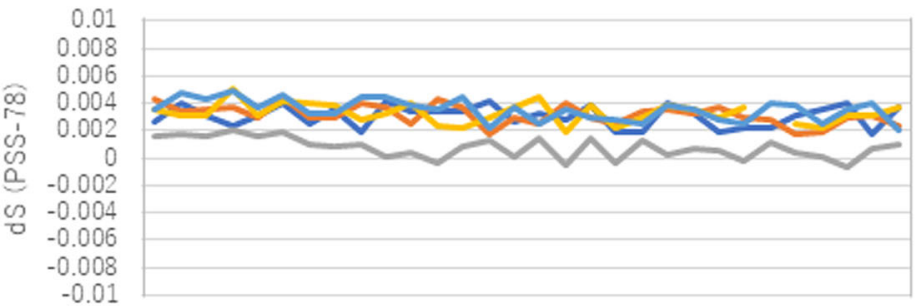

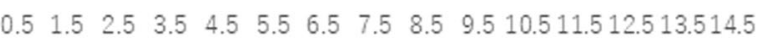

Ex1 Ex —Ex —Ex4 Ex5 Time (minues)

Fig. 9 (See legend on next page.) 
(See figure on previous page.)

Fig. 9 a Temperature (upper) and salinity (lower) differences (shown in the legend as "dT" and "dS," respectively) of measurements between SBE41 and SBE3 and 4 sensors during four experiments (Ex1 Ex4) for float S/N 8085 of J-Calibration. J-Calibration system uses cooling packs, adiabatic materials, and a Vinyl greenhouse to keep a uniform environment during the experiments. In 15 min allotted for each measurement, actual calibration is done in 5 min when the $\mathrm{dT}$ and dS are within $\pm 0.01^{\circ} \mathrm{C}$ and \pm 0.01 PSS-78, respectively. $\mathbf{b}$ The same as Fig. 9 a except for 5 experiments (Ex1 Ex5) for float S/N F0584 of J-Calibration

degassed water is kept in the same laboratory room throughout.

Here, we use a $\mathrm{NaCl}$ solution seawater as the artificial seawater in both SBE- and J-Calibration, because handling and creating the artificial seawater is easier than using real seawater. In the manufacturer SBE, the SBE41 sensor calibration is conducted using artificial seawater, in the same manner as our method. When using real seawater for SBE3 and 4 calibration, the coefficients and slope are different from those found when using the artificial seawater. To avoid this discrepancy, we corrected the salinity measurement of SBE3 and 4 using a salinometer "Autosal" (Guildline Instruments 1981) to modify the coefficients and slope of the equation, which is the same method used by the manufacturer SBE.

\section{Results}

\section{Experiments using J-Calibration system}

J-Calibration was carried out for Navis and APEX type floats, which were delivered to JAMSTEC from 2017 to 2018. The number of floats in total was 33, and that of the calibration experiments was 88 , as listed in Table 6. Measurement values of temperature, conductivity, and salinity calculated from pressure, and conductivity and temperature for SBE41 and SBE3 and 4 standard sensors are described. The differences between the three parameters between the SBE41 and the standard sensors are also shown. The measurement values of temperature and salinity are approximately $22^{\circ} \mathrm{C}$ and 35.0 PSS-78, respectively, and the differences are within the order of $10^{-3}$. Based on the values in Table 6, all experiments in JCalibration are clearly stable. Both J-Calibration and SBE-Calibration were conducted 8 times for 3 of the 33 floats to evaluate the accuracy and stability of JCalibration in comparison with SBE-Calibration (Table 7). The three floats were the only Navis type we were able to obtain permission from the manufacturer to remove the SBE41 sensors from the float body for SBE-Calibration. Using the artificial seawater (salinity concentration of about 35 PSS-78) that is already degassed, we calculated a difference of temperature and conductivity between SBE41 and
SBE3 and 4 standard sensors to evaluate J-Calibration, averaging those measurement values for about $5 \mathrm{~min}$.

Table 8 shows temperature, conductivity, and salinity differences for 8 experiments of 3 floats using JCalibration. Table 9 shows the average and statistical values of 8 experiments of SBE-Calibration for the 3 floats. Since the salinity differences between SBE41 and SBE3 and the 4 standard sensors are within \pm 0.01 PSS-78 through all the experiments of SBECalibration, SBE41 sensors were considered to satisfy the Argo criteria with the same result as in JCalibration. Considering the standard deviation of temperature difference $\left(\Delta \mathrm{T} \sim \pm 0.0015^{\circ} \mathrm{C}\right)$ and salinity difference $(\Delta S \sim \pm 0.0033$ PSS-78), those three SBE41 sensor samples are all stable and satisfy the criteria for Argo accuracy. The results of both SBE- and JCalibration and their statistical values demonstrate that J-Calibration can accurately validate floats without any faults.

\section{Evaluation of J-Calibration results}

Figure 10 shows a scatter plot of conductivity differences between SBE41 and SBE 4 standard sensors using J-Calibration and SBE-Calibration. Regarding the three SBE41 sensors (S/N 914, 918, and 922), we conducted SBE-Calibration at 7 point-calibrations $(\bullet$ marks) in the same manner as the manufacturer SBE and J-Calibration ( $\boldsymbol{\Delta}$ marks). The result was that the differences in conductivity tend to be small within mostly $\pm 0.5 \times 10^{-3} \mathrm{~S} \mathrm{~m}^{-1}$, although two sensors (S/N 914 and 918 ) were biased a little to the positive side, while one sensor (S/N: 922) had a small negative bias around $-0.5 \times 10^{-3} \mathrm{~S} \mathrm{~m}^{-1}$. In those cases, we can judge that the three SBE41 sensors are healthy based on SBE-Calibration results. Here, we define two criteria for failure of a sensor (red dashed; over \pm 0.015 PSS-78 at $5.2 \mathrm{~S} \mathrm{~m}^{-1}$ ) and re-calibration (red dotted; \pm 0.0075 PSS-78 at $5.2 \mathrm{~S} \mathrm{~m}^{-1}$ ) as references. In the case of faults, we could find large biases with both positive or negative signs outside of the criteria lines of the fault sensors, and these may be caused by difficulty during transportation or by fluctuations during experiments.

The differences of conductivity between SBE41 and the SBE4 standard sensors in J-Calibration (88 times 
Table 6 Specification of 88 experiments of J-calibration based on 33 floats. All SBE41 sensors are examined with J-Calibration more than twice

\begin{tabular}{|c|c|c|c|c|c|c|c|c|c|c|c|}
\hline \multirow{2}{*}{$\begin{array}{l}\text { Float } \\
\text { type }\end{array}$} & \multirow{2}{*}{$\begin{array}{l}\text { Float } \\
\text { S/N }\end{array}$} & \multirow{2}{*}{$\begin{array}{l}\text { Date } \\
(2017)\end{array}$} & \multicolumn{3}{|c|}{ Float (SBE41) } & \multicolumn{3}{|c|}{ Standard sensor } & \multicolumn{3}{|c|}{ Difference $\left(\times 10^{-3}\right)$} \\
\hline & & & $\overline{\mathrm{T}\left[{ }^{\circ} \mathrm{C}\right]}$ & $C\left[\mathrm{Sm}^{-1}\right]$ & $\bar{S}$ [PSS-78] & $\overline{\mathrm{T}\left[{ }^{\circ} \mathrm{C}\right]}$ & $\mathrm{C}\left[\mathrm{Sm}^{-1}\right]$ & $\bar{S}[$ PSS-78] & $\overline{\Delta \mathrm{T}\left[{ }^{\circ} \mathrm{C}\right]}$ & $\Delta C\left[\mathrm{~S} \mathrm{~m}^{-1}\right]$ & $\Delta S$ [PSS78] \\
\hline APEX & 7849 & August 14 & 23.2411 & 5.11240 & 34.9093 & 23.2389 & 5.11326 & 34.9177 & 2.26 & -0.861 & -8.40 \\
\hline APEX & 7849 & August 21 & 22.4158 & 5.02942 & 34.9253 & 22.4158 & 5.03046 & 34.9334 & -0.03 & -1.035 & -8.05 \\
\hline APEX & 7849 & August 21 & 22.4637 & 5.05372 & 35.0764 & 22.4664 & 5.05522 & 35.0859 & -2.70 & -1.500 & -9.53 \\
\hline APEX & 7849 & August 24 & 22.2976 & 5.00687 & 34.8440 & 22.2990 & 5.00818 & 34.8531 & -1.34 & -1.306 & -9.14 \\
\hline APEX & 7849 & August 24 & 23.1198 & 5.09107 & 34.8415 & 23.1229 & 5.09260 & 34.8509 & -3.03 & -1.528 & -9.35 \\
\hline APEX & 7849 & April 26 & 22.5755 & 5.04418 & 34.9123 & 22.5779 & 5.04475 & 34.9148 & -2.36 & -0.566 & -2.51 \\
\hline APEX & 7849 & April 26 & 22.1196 & 4.99755 & 34.9140 & 22.1210 & 4.99804 & 34.9167 & -1.43 & -0.489 & -2.69 \\
\hline APEX & 7907 & August 14 & 23.2399 & 5.11377 & 34.9208 & 23.2390 & 5.11328 & 34.9177 & 0.81 & 0.489 & 3.12 \\
\hline APEX & 7907 & August 21 & 22.4158 & 5.03079 & 34.9359 & 22.4160 & 5.03048 & 34.9334 & -0.20 & 0.310 & 2.58 \\
\hline APEX & 7907 & August 21 & 22.4643 & 5.05513 & 35.0869 & 22.4666 & 5.05524 & 35.0859 & -2.27 & -0.109 & 0.98 \\
\hline APEX & 7907 & August 24 & 22.2980 & 5.00827 & 34.8546 & 22.2992 & 5.00821 & 34.8531 & -1.21 & 0.066 & 1.48 \\
\hline APEX & 7907 & August 24 & 23.1198 & 5.09252 & 34.8528 & 23.1231 & 5.09262 & 34.8509 & -3.34 & -0.097 & 1.90 \\
\hline APEX & 8084 & August 15 & 22.5776 & 5.04404 & 34.9095 & 22.5755 & 5.04347 & 34.9068 & 2.12 & 0.568 & 2.73 \\
\hline APEX & 8084 & August 17 & 22.4651 & 5.02755 & 34.8712 & 22.4643 & 5.02723 & 34.8694 & 0.83 & 0.321 & 1.83 \\
\hline APEX & 8084 & August 22 & 21.9148 & 4.93533 & 34.5895 & 21.9119 & 4.93483 & 34.5879 & 2.91 & 0.496 & 1.57 \\
\hline APEX & 8084 & August 22 & 22.2110 & 4.96531 & 34.5882 & 22.2100 & 4.96501 & 34.5867 & 1.04 & 0.295 & 1.48 \\
\hline APEX & 8085 & August 15 & 22.5765 & 5.04361 & 34.9071 & 22.5756 & 5.04349 & 34.9068 & 0.83 & 0.119 & 0.26 \\
\hline APEX & 8085 & August 17 & 22.4653 & 5.02741 & 34.8700 & 22.4644 & 5.02724 & 34.8694 & 0.92 & 0.172 & 0.60 \\
\hline APEX & 8085 & August 22 & 21.9101 & 4.93473 & 34.5886 & 21.9121 & 4.93486 & 34.5879 & -2.05 & -0.124 & 0.67 \\
\hline APEX & 8085 & August 22 & 22.2086 & 4.96498 & 34.5875 & 22.2101 & 4.96503 & 34.5867 & -1.49 & -0.051 & 0.79 \\
\hline APEX & 8086 & August 15 & 22.5761 & 5.04387 & 34.9094 & 22.5758 & 5.04350 & 34.9068 & 0.37 & 0.371 & 2.59 \\
\hline APEX & 8086 & August 17 & 22.4644 & 5.02713 & 34.8685 & 22.4646 & 5.02726 & 34.8694 & -0.15 & -0.130 & -0.90 \\
\hline APEX & 8086 & August 22 & 21.9117 & 4.93471 & 34.5871 & 21.9124 & 4.93488 & 34.5879 & -0.70 & -0.172 & -0.79 \\
\hline APEX & 8086 & August 22 & 22.2105 & 4.96497 & 34.5860 & 22.2103 & 4.96505 & 34.5867 & 0.20 & -0.076 & -0.76 \\
\hline APEX & 8087 & August 16 & 23.0446 & 5.09439 & 34.9267 & 23.0430 & 5.09393 & 34.9245 & 1.67 & 0.457 & 2.20 \\
\hline APEX & 8087 & August 23 & 22.1860 & 5.00377 & 34.9094 & 22.1870 & 5.00357 & 34.9070 & -1.05 & 0.200 & 2.41 \\
\hline APEX & 8087 & August 23 & 22.4708 & 5.03274 & 34.9071 & 22.4715 & 5.03246 & 34.9044 & -0.69 & 0.279 & 2.72 \\
\hline APEX & 8088 & August 16 & 23.0416 & 5.09384 & 34.9250 & 23.0431 & 5.09395 & 34.9245 & -1.59 & -0.109 & 0.42 \\
\hline APEX & 8088 & August 23 & 22.1851 & 5.00322 & 34.9058 & 22.1873 & 5.00360 & 34.9070 & -2.22 & -0.379 & -1.19 \\
\hline APEX & 8088 & August 23 & 22.4700 & 5.03232 & 34.9045 & 22.4716 & 5.03248 & 34.9044 & -1.64 & -0.158 & 0.08 \\
\hline APEX & 8089 & August 16 & 23.0416 & 5.09394 & 34.9256 & 23.0433 & 5.09396 & 34.9245 & -1.65 & -0.027 & 1.11 \\
\hline APEX & 8089 & August 23 & 22.1877 & 5.00345 & 34.9054 & 22.1875 & 5.00362 & 34.9070 & 0.19 & -0.179 & -1.55 \\
\hline APEX & 8089 & August 23 & 22.4695 & 5.03235 & 34.9051 & 22.4718 & 5.03250 & 34.9044 & -2.37 & -0.146 & 0.77 \\
\hline APEX & 8262 & April 16 & 22.9391 & 5.09810 & 35.0395 & 22.9372 & 5.09758 & 35.0370 & 1.89 & 0.514 & 2.46 \\
\hline APEX & 8262 & April 16 & 22.6803 & 5.07164 & 35.0417 & 22.6798 & 5.07106 & 35.0376 & 0.49 & 0.575 & 4.07 \\
\hline APEX & 8263 & April 16 & 22.9372 & 5.09791 & 35.0396 & 22.9374 & 5.09761 & 35.0370 & -0.24 & 0.306 & 2.56 \\
\hline APEX & 8263 & April 16 & 22.6802 & 5.07151 & 35.0408 & 22.6799 & 5.07108 & 35.0376 & 0.28 & 0.437 & 3.16 \\
\hline APEX & 8264 & April 16 & 22.9365 & 5.09793 & 35.0399 & 22.9376 & 5.09763 & 35.0370 & -1.08 & 0.302 & 2.82 \\
\hline APEX & 8264 & April 16 & 22.6793 & 5.07158 & 35.0421 & 22.6801 & 5.07109 & 35.0376 & -0.80 & 0.493 & 4.46 \\
\hline APEX & 8265 & April 17 & 23.1576 & 5.11128 & 34.9669 & 23.1565 & 5.11127 & 34.9678 & 1.18 & 0.005 & -0.90 \\
\hline APEX & 8265 & April 17 & 23.0436 & 5.09961 & 34.9678 & 23.0432 & 5.09955 & 34.9677 & 0.32 & 0.052 & 0.15 \\
\hline APEX & 8266 & April 17 & 23.1586 & 5.11174 & 34.9697 & 23.1567 & 5.11130 & 34.9678 & 1.87 & 0.440 & 1.90 \\
\hline
\end{tabular}


Table 6 Specification of 88 experiments of J-calibration based on 33 floats. All SBE41 sensors are examined with J-Calibration more than twice (Continued)

\begin{tabular}{|c|c|c|c|c|c|c|c|c|c|c|c|}
\hline \multirow{2}{*}{$\begin{array}{l}\text { Float } \\
\text { type }\end{array}$} & \multirow{2}{*}{$\begin{array}{l}\text { Float } \\
\mathrm{S} / \mathrm{N}\end{array}$} & \multirow{2}{*}{$\begin{array}{l}\text { Date } \\
(2017)\end{array}$} & \multicolumn{3}{|c|}{ Float (SBE41) } & \multicolumn{3}{|c|}{ Standard sensor } & \multicolumn{3}{|c|}{ Difference $\left(\times 10^{-3}\right)$} \\
\hline & & & $\mathrm{T}\left[{ }^{\circ} \mathrm{C}\right]$ & $\mathrm{C}\left[\mathrm{Sm}^{-1}\right]$ & $\mathrm{S}$ [PSS-78] & $\mathrm{T}\left[{ }^{\circ} \mathrm{C}\right]$ & $\mathrm{C}\left[\mathrm{Sm}^{-1}\right]$ & $\mathrm{S}$ [PSS-78] & $\Delta \mathrm{T}\left[{ }^{\circ} \mathrm{C}\right]$ & $\Delta C\left[\mathrm{~S} \mathrm{~m}^{-1}\right]$ & $\Delta \mathrm{S}[\mathrm{PSS} 78]$ \\
\hline APEX & 8266 & April 17 & 23.0446 & 5.10010 & 34.9708 & 23.0434 & 5.09957 & 34.9677 & 1.22 & 0.533 & 3.14 \\
\hline APEX & 8267 & April 17 & 23.1586 & 5.11187 & 34.9707 & 23.1570 & 5.11133 & 34.9678 & 1.65 & 0.546 & 2.89 \\
\hline APEX & 8267 & April 17 & 23.0446 & 5.10014 & 34.9711 & 23.0436 & 5.09959 & 34.9677 & 1.03 & 0.553 & 3.44 \\
\hline APEX & 8416 & April 18 & 23.2711 & 5.12112 & 34.9524 & 23.2725 & 5.12115 & 34.9515 & -1.44 & -0.027 & 0.93 \\
\hline APEX & 8416 & April 18 & 22.8732 & 5.08021 & 34.9539 & 22.8736 & 5.08000 & 34.9519 & -0.43 & 0.218 & 2.02 \\
\hline APEX & 8417 & April 18 & 22.8749 & 5.08081 & 34.9571 & 22.8737 & 5.08001 & 34.9519 & 1.21 & 0.800 & 5.22 \\
\hline APEX & 8417 & April 20 & 24.1304 & 5.19782 & 34.8593 & 24.1308 & 5.19756 & 34.8571 & -0.35 & 0.260 & 2.22 \\
\hline APEX & 8417 & April 20 & 23.7884 & 5.16263 & 34.8609 & 23.7872 & 5.16198 & 34.8569 & 1.24 & 0.651 & 3.97 \\
\hline APEX & 8418 & April 18 & 23.2715 & 5.12142 & 34.9544 & 23.2728 & 5.12117 & 34.9515 & -1.25 & 0.253 & 2.93 \\
\hline APEX & 8418 & April 18 & 22.8737 & 5.08046 & 34.9554 & 22.8739 & 5.08002 & 34.9519 & -0.16 & 0.439 & 3.52 \\
\hline APEX & 8419 & April 19 & 23.7940 & 5.16733 & 34.8922 & 23.7948 & 5.16709 & 34.8898 & -0.77 & 0.235 & 2.39 \\
\hline APEX & 8419 & April 19 & 23.6412 & 5.15155 & 34.8925 & 23.6414 & 5.15119 & 34.8896 & -0.25 & 0.361 & 2.95 \\
\hline APEX & 8420 & April 19 & 23.7945 & 5.16744 & 34.8927 & 23.7950 & 5.16712 & 34.8898 & -0.58 & 0.320 & 2.89 \\
\hline APEX & 8420 & April 19 & 23.6422 & 5.15175 & 34.8932 & 23.6416 & 5.15121 & 34.8896 & 0.61 & 0.541 & 3.64 \\
\hline APEX & 8421 & April 19 & 23.7964 & 5.16765 & 34.8928 & 23.7953 & 5.16715 & 34.8898 & 1.07 & 0.505 & 2.99 \\
\hline APEX & 8421 & April 19 & 23.6424 & 5.15177 & 34.8932 & 23.6417 & 5.15122 & 34.8896 & 0.64 & 0.544 & 3.64 \\
\hline APEX & 8422 & April 20 & 24.1284 & 5.19773 & 34.8602 & 24.1302 & 5.19750 & 34.8571 & -1.77 & 0.231 & 3.13 \\
\hline APEX & 8422 & April 20 & 23.7866 & 5.16247 & 34.8612 & 23.7869 & 5.16195 & 34.8569 & -0.33 & 0.529 & 4.28 \\
\hline APEX & 8423 & April 20 & 24.1291 & 5.19774 & 34.8597 & 24.1305 & 5.19753 & 34.8571 & -1.33 & 0.210 & 2.63 \\
\hline APEX & 8423 & April 20 & 23.7883 & 5.16267 & 34.8613 & 23.7871 & 5.16196 & 34.8569 & 1.23 & 0.703 & 4.37 \\
\hline Navis & 584 & August 14 & 23.2405 & 5.11382 & 34.9207 & 23.2387 & 5.11325 & 34.9177 & 1.74 & 0.575 & 3.04 \\
\hline Navis & 584 & August 21 & 22.4179 & 5.03106 & 34.9364 & 22.4157 & 5.03044 & 34.9334 & 2.24 & 0.620 & 3.03 \\
\hline Navis & 584 & August 21 & 22.4685 & 5.05551 & 35.0864 & 22.4662 & 5.05521 & 35.0859 & 2.29 & 0.300 & 0.49 \\
\hline Navis & 584 & August 24 & 22.3003 & 5.00872 & 34.8562 & 22.2987 & 5.00815 & 34.8531 & 1.62 & 0.569 & 3.14 \\
\hline Navis & 584 & August 24 & 23.1222 & 5.09297 & 34.8542 & 23.1226 & 5.09257 & 34.8508 & -0.44 & 0.392 & 3.36 \\
\hline Navis & 913 & April 23 & 23.3763 & 5.14524 & 35.0538 & 23.3767 & 5.14491 & 35.0509 & -0.39 & 0.334 & 2.87 \\
\hline Navis & 913 & April 23 & 23.1729 & 5.12431 & 35.0550 & 23.1740 & 5.12398 & 35.0516 & -1.10 & 0.330 & 3.41 \\
\hline Navis & 914 & April 23 & 23.3775 & 5.14553 & 35.0551 & 23.3769 & 5.14492 & 35.0509 & 0.66 & 0.614 & 4.18 \\
\hline Navis & 914 & April 23 & 23.1745 & 5.12461 & 35.0560 & 23.1741 & 5.12398 & 35.0516 & 0.40 & 0.626 & 4.49 \\
\hline Navis & 915 & April 23 & 23.3783 & 5.14542 & 35.0536 & 23.3770 & 5.14493 & 35.0509 & 1.25 & 0.487 & 2.74 \\
\hline Navis & 915 & April 23 & 23.1742 & 5.12440 & 35.0547 & 23.1741 & 5.12399 & 35.0516 & 0.06 & 0.412 & 3.12 \\
\hline Navis & 916 & April 24 & 23.3022 & 5.12756 & 34.9771 & 23.3033 & 5.12758 & 34.9764 & -1.11 & -0.020 & 0.73 \\
\hline Navis & 916 & April 24 & 22.6258 & 5.05820 & 34.9810 & 22.6263 & 5.05816 & 34.9800 & -0.49 & 0.033 & 1.01 \\
\hline Navis & 917 & April 24 & 23.3056 & 5.12839 & 34.9807 & 23.3034 & 5.12759 & 34.9764 & 2.23 & 0.796 & 4.33 \\
\hline Navis & 917 & April 24 & 22.6273 & 5.05887 & 34.9850 & 22.6264 & 5.05817 & 34.9800 & 0.94 & 0.697 & 5.03 \\
\hline Navis & 918 & April 24 & 22.6274 & 5.05795 & 34.9778 & 22.6264 & 5.05818 & 34.9800 & 0.98 & -0.222 & -2.14 \\
\hline Navis & 918 & April 26 & 22.5774 & 5.04438 & 34.9124 & 22.5778 & 5.04474 & 34.9148 & -0.44 & -0.359 & -2.44 \\
\hline Navis & 918 & April 26 & 22.1215 & 4.99783 & 34.9147 & 22.1209 & 4.99803 & 34.9167 & 0.61 & -0.202 & -2.08 \\
\hline Navis & 919 & April 25 & 21.9950 & 4.98649 & 34.9276 & 21.9949 & 4.98577 & 34.9221 & 0.08 & 0.715 & 5.56 \\
\hline Navis & 919 & April 25 & 22.4174 & 5.02985 & 34.9273 & 22.4195 & 5.02940 & 34.9222 & -2.06 & 0.449 & 5.16 \\
\hline Navis & 920 & April 25 & 21.9948 & 4.98670 & 34.9293 & 21.9949 & 4.98578 & 34.9221 & -0.08 & 0.918 & 7.29 \\
\hline Navis & 920 & April 25 & 22.4186 & 5.03011 & 34.9284 & 22.4195 & 5.02940 & 34.9222 & -0.90 & 0.708 & 6.24 \\
\hline
\end{tabular}


Table 6 Specification of 88 experiments of J-calibration based on 33 floats. All SBE41 sensors are examined with J-Calibration more than twice (Continued)

\begin{tabular}{|c|c|c|c|c|c|c|c|c|c|c|c|}
\hline \multirow{2}{*}{$\begin{array}{l}\text { Float } \\
\text { type }\end{array}$} & \multirow{2}{*}{$\begin{array}{l}\text { Float } \\
\text { S/N }\end{array}$} & \multirow{2}{*}{$\begin{array}{l}\text { Date } \\
(2017)\end{array}$} & \multicolumn{3}{|c|}{ Float (SBE41) } & \multicolumn{3}{|c|}{ Standard sensor } & \multicolumn{3}{|c|}{ Difference $\left(\times 10^{-3}\right)$} \\
\hline & & & $\mathrm{T}\left[{ }^{\circ} \mathrm{C}\right]$ & $\mathrm{C}\left[\mathrm{Sm}^{-1}\right]$ & $\mathrm{S}$ [PSS-78] & $\mathrm{T}\left[{ }^{\circ} \mathrm{C}\right]$ & $\mathrm{C}\left[\mathrm{Sm}^{-1}\right]$ & S [PSS-78] & $\Delta \mathrm{T}\left[{ }^{\circ} \mathrm{C}\right]$ & $\Delta C\left[\mathrm{~S} \mathrm{~m}^{-1}\right]$ & $\Delta \mathrm{S}[\mathrm{PSS} 78]$ \\
\hline Navis & 921 & April 25 & 21.9928 & 4.98619 & 34.9270 & 21.9950 & 4.98578 & 34.9221 & -2.19 & 0.409 & 4.99 \\
\hline Navis & 921 & April 25 & 22.4156 & 5.02955 & 34.9265 & 22.4196 & 5.02941 & 34.9222 & -4.04 & 0.140 & 4.33 \\
\hline Navis & 922 & April 26 & 22.5770 & 5.04524 & 34.9193 & 22.5777 & 5.04473 & 34.9148 & -0.69 & 0.505 & 4.48 \\
\hline Navis & 922 & April 26 & 22.1209 & 4.99860 & 34.9212 & 22.1208 & 4.99802 & 34.9167 & 0.09 & 0.576 & 4.45 \\
\hline
\end{tabular}

based on the other sensors) are also over-plotted. As the temperature at one point $\left(22^{\circ} \mathrm{C}\right.$ corresponding to $5.2 \mathrm{~S} \mathrm{~m}^{-1}$ ) is chosen, all plots are gathered around conductivities of $5.0-5.3 \mathrm{~S} \mathrm{~m}^{-1}$. Generally, the conductivity differences of all J-Calibration are distributed within \pm 0.0075 PSS-78, corresponding to salinity values (red dotted lines), although several experiments were outside of these differences. However, all the conductivity sensors are still judged as sufficient for Argo criteria, namely, \pm 0.01 PSS-78 for salinity. As a result, no conductivity sensors on SBE41 needed to be returned to the manufacturer and repaired. If a faulty sensor of SBE41 existed, it is expected that the difference from the standard sensor will fall outside the fault-tolerance threshold, requiring the sensor to be returned to the manufacturer. In this case, we would need further information from the manufacturer to analyze other technical data and investigate whether the case is a serious and systematic error.

Figure 11 shows the frequency histograms of differences between the SBE41 and SBE3 and 4 standard sensors for temperature (a), conductivity (b), and salinity (c) in J-Calibration. In the 88 experiments (see Table 6), the histogram of temperature difference is almost a normal distribution, with 0 at the center of the histogram (Fig. 11a). The histograms of conductivity and salinity (Fig. 11b, c) have a positive bias at a center of $0.19 \times 10^{-3} \mathrm{~S} \mathrm{~m}^{-1}$ and $1.6 \times 10^{-3}$ PSS-78, respectively. The positive biases in JCalibration are the same as described in Fig. 10, but all the sensors satisfy the Argo criteria.

Furthermore, we investigated the dependency of the salinity concentration on the differences between SBE41 and the standard sensors in all calibration experiments of both SBE-Calibration and J-Calibration
(Fig. 12). The salinity concentration in SBECalibration was set to 34.975 PSS-78, while that in JCalibration is dispersed between 34.85 and 35.10 PSS78. There is no systematic dependency or bias on the concentration of artificial seawater salinity for salinity differences. This means that we do not need to strictly control the salinity concentration of the seawater, which is different from SBE-Calibration. Based on those experiments, we summarize the results of 33 floats in J-Calibration and 3 floats in SBE-Calibration as follows:

1. Accuracy and precision of J-Calibration for temperature and conductivity sensors are enough to screen faulty sensors of SBE41.

2. Conductivity and salinity differences in JCalibration have a small positive bias but this influence on the screening result can be ignored.

3. It is not necessary to control the salinity concentration of artificial seawater in J-Calibration.

Although the number of experiments for J-Calibration is not still enough to be significant at this time, the J-Calibration system is effective to find faulty sensors and to avoid deployment of faulty floats in advance, with similar accuracy to that of the SBE-Calibration system.

\section{Discussion}

In the "Results" section, we confirmed the screening accuracy of J-Calibration for temperature and conductivity. Here, we investigate the stability of J-Calibration depending on different environments such as seasonality and room conditioning, and J-Calibration performance regarding the screening result is correct or faulty by

Table 7 Float and sensor S/N and calibration date of SBE-Calibration and J-Calibration for the three SBE41 sensors

\begin{tabular}{lllllll}
\hline Float type & S/N & Sensor S/N & SBE-Calib. (no. of exp) & Experiment date & J-Calib. (no. of exp) & Experiment date \\
\hline Navis (SBE) & 914 & 10,532 & 3 & April 6, 2018 & 2 & April 23, 2018 \\
Navis (SBE) & 918 & 10,540 & 3 & April 6, 2018 & 3 & April 24, 2018 \\
Navis (SBE) & 922 & 10,558 & 2 & April 6, 2018 & 2 & April 26, 2018 \\
\hline
\end{tabular}

Note: SBE-Calibration is repeatedly conducted one or two times for each sensor 
Table 8 Eight experiments of J-Calibration for the three sensors (S/N 914, 918, and 922).

\begin{tabular}{|c|c|c|c|c|c|c|c|c|c|c|}
\hline \multirow{2}{*}{$\begin{array}{l}\text { Float } \\
\text { number }\end{array}$} & \multirow[t]{2}{*}{ Exp. Date } & \multicolumn{3}{|c|}{ Float data $\left(X_{\text {float }}\right)$} & \multicolumn{3}{|c|}{ Standard sensor data $\left(\mathrm{X}_{\mathrm{ref}}\right)$} & \multicolumn{3}{|c|}{ Difference $\left(X_{\text {float }}-X_{\text {ref }}\right)$} \\
\hline & & $\overline{T\left({ }^{\circ} \mathrm{C}\right)}$ & $C\left(\mathrm{~S} \mathrm{~m}^{-1}\right)$ & S (PSS-78) & $\overline{T\left({ }^{\circ} \mathrm{C}\right)}$ & $C\left(\mathrm{~S} \mathrm{~m}^{-1}\right)$ & S (PSS-78) & $\overline{\Delta T\left(\times 10^{-3}{ }^{\circ} \mathrm{C}\right)}$ & $\Delta C\left(\times 10^{-3} \mathrm{~S} \mathrm{~m}^{-1}\right)$ & $\Delta S\left(\times 10^{-3}\right.$ PSS78) \\
\hline 914 & April 23, 2018 & 23.38 & 5.146 & 35.06 & 23.38 & 5.145 & 35.05 & 0.66 & 0.614 & 4.18 \\
\hline 914 & April 23, 2018 & 23.17 & 5.125 & 35.06 & 23.17 & 5.124 & 35.05 & 0.40 & 0.626 & 4.49 \\
\hline 918 & April 24, 2018 & 22.63 & 5.058 & 34.98 & 22.63 & 5.058 & 34.98 & 0.98 & -0.222 & -2.14 \\
\hline 918 & April 26, 2018 & 22.58 & 5.044 & 34.91 & 22.58 & 5.045 & 34.91 & -0.44 & -0.359 & -2.44 \\
\hline 918 & April 26, 2018 & 22.12 & 4.998 & 34.91 & 22.12 & 4.998 & 34.92 & 0.61 & -0.202 & -2.08 \\
\hline 922 & April 26, 2018 & 22.58 & 5.045 & 34.92 & 22.58 & 5.045 & 34.91 & -0.69 & 0.505 & 4.48 \\
\hline 922 & April 26, 2018 & 22.12 & 4.999 & 34.92 & 22.12 & 4.998 & 34.92 & 0.09 & 0.576 & 4.45 \\
\hline
\end{tabular}

Differences between SBE41 sensors and standard sensors for temperature, conductivity, and salinity $(\Delta \mathrm{T}, \Delta \mathrm{C}$, and $\Delta \mathrm{S})$ are described. Units are $10^{-3}{ }^{\circ} \mathrm{C}, 10^{-3} \mathrm{~S} \mathrm{~m}^{-1}$, and $10^{-3}$ PSS-78, respectively. In those experiments, the artificial sea water is set to 35 PSS-78 for salinity and $22-24^{\circ} \mathrm{C}$ for temperature

comparing with rQCed data after float deployment. Then, the small positive bias described in the "Results" section is investigated and related to the use of artificial seawater.

\section{J-Calibration system assessment: seasonal dependency}

Based on the importance of stable room temperature as shown with some of the items in Table 2, we investigate the seasonal dependency of J-Calibration results. Here, we use the experiment results of 3 SBE41 sensors (S/N 914, 918, and 922) in April 2018 (winter) and August 2017 (summer) when the average outside temperatures are $7.4{ }^{\circ} \mathrm{C}$ and $21.7^{\circ} \mathrm{C}$ in Mutsu City in Japan, respectively (based on monthly air temperature climatology from the Japan Meteorological Agency). In Mutsu City, room heating and cooling devices are used in April to August. As shown in the "Methods/Experimental" section, the air conditioner is stopped during the experiments, and the experiment environment is separated from the room environment to achieve greater stability by using a vinyl greenhouse. Figure 13 shows the histograms of the results for temperature (a), conductivity (b), and salinity (c) for each experimental season (April, blue; August, orange), which is separated by the results shown in Fig. 11. The histogram of temperature differences from standard sensors is an almost normal distribution around 0 in both seasons.
While conductivity and salinity distributions are different from temperature, there is a larger positive bias in April than in August. Vertical temperature distribution inside the greenhouse is observed between the floor and sensor level due to a temperature stratification, especially in April. In the winter season, the heater warms the upper layer of the atmosphere while the floor tends to be cold. This temperature discrepancy causes strengthened vertical air stratification. In fact, during the experiments, the average temperature difference between the height at the conductivity sensor $(160 \mathrm{~cm})$ and the float body $(60 \mathrm{~cm})$ reaches $0.5^{\circ} \mathrm{C}$ in experiments conducted in April when it is still the winter season in Mutsu. By cooling from the floor of the laboratory, the contrast of air temperature between the upper and lower level becomes large, which causes the conductivity sensor to be cold due to heat loss from the floor. On the other hand, cooling with the air conditioner causes vertical air mixing and such stratification is not formed. Therefore, careful attention should be paid to the vertical temperature difference during J-Calibration experiments in the winter or early spring seasons.

In Fig. 13, although almost all histograms show a Gaussian distribution in both SBE-Calibration and JCalibration, these histograms are dispersed and widely spread. If the dispersion generally appears in every experiment on the same sensors, J-Calibration

Table 9 Average, standard deviation, minimum and maximum values for temperature, conductivity, and salinity of 8 SBE-Calibration results

\begin{tabular}{llllllllll}
\hline & Temp (float) & Cond. (float) & Sal (float) & Temp (Ref.) & Cond. (Ref.) & Sal. (Ref.) & $\Delta \mathrm{T}\left(\times 10^{-3}\right)$ & $\Delta \mathrm{C}\left(\times 10^{-3}\right)$ & $\Delta \mathrm{S}\left(\times 10^{-3}\right)$ \\
\hline Average & 22.8337 & 5.0714 & 34.9161 & 22.8339 & 5.0712 & 34.9145 & -0.1471 & 0.1936 & 1.6148 \\
Standard deviation & 0.5665 & 0.0634 & 0.1088 & 0.5663 & 0.0633 & 0.1084 & 1.4358 & 0.4754 & 3.2851 \\
Maximum & 24.1304 & 5.1978 & 35.0869 & 24.1308 & 5.1976 & 35.0859 & 2.9100 & 0.9180 & 7.2900 \\
Minimum & 21.9101 & 4.9347 & 34.5860 & 21.9119 & 4.9348 & 34.5867 & -4.0400 & -1.5280 & -9.5300 \\
\hline
\end{tabular}

Note: Temp temperature, Cond conductivity, Sal salinity, Ref. reference sensors 


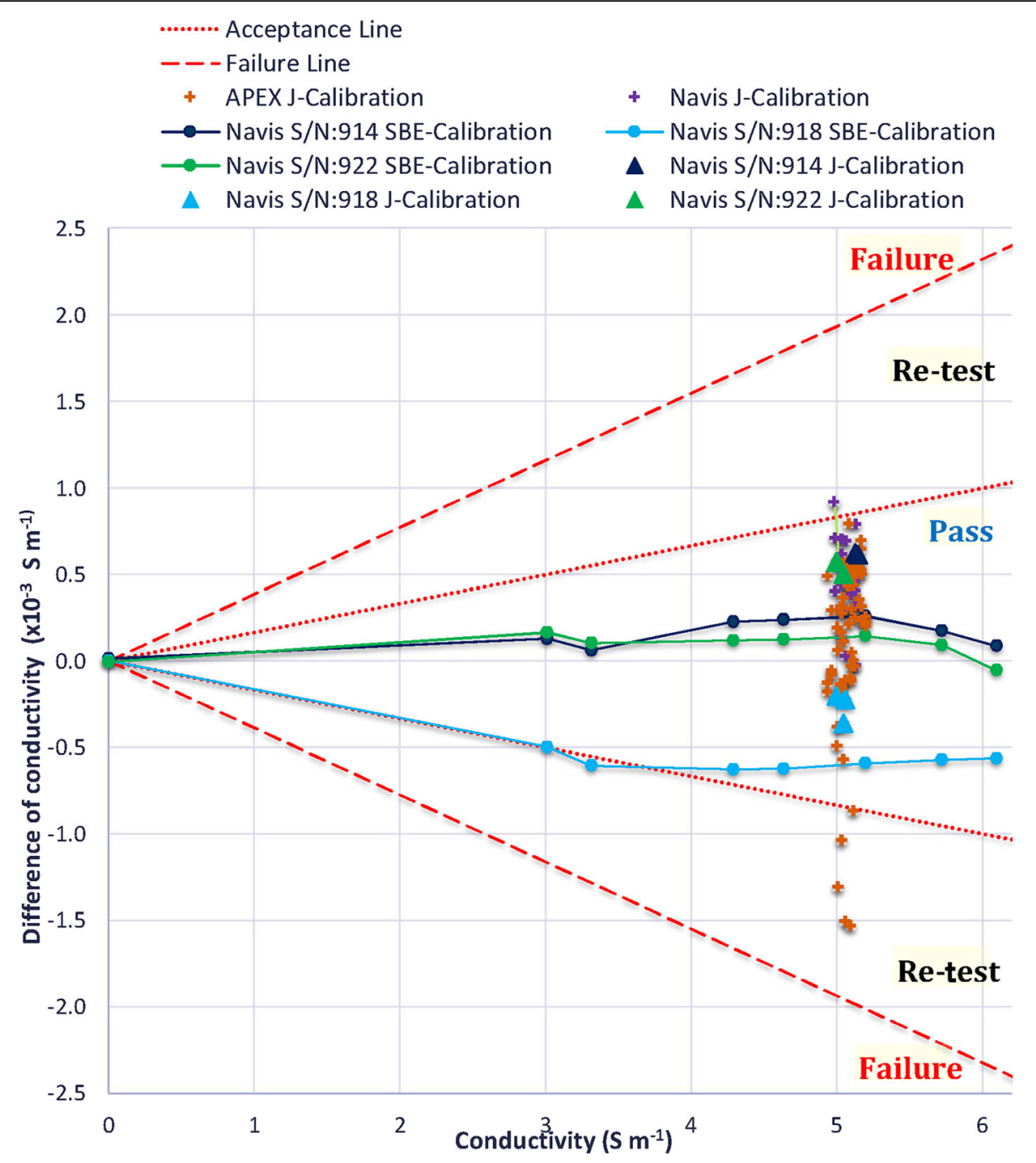

Fig. 10 Conductivity calibration results to judge whether sensors are acceptable or not. $X$-axis is conductivity on standard sensor, $Y$-axis is conductivity differences of SBE41 and standard sensor. $\bullet$ and $\boldsymbol{\Delta}$ represent SBE-Calibration and J-Calibration results (S/N 914, 918, and 922), respectively. Colors (dark blue, light blue, and green) indicate sensor S/N (914, 918, and 922), respectively. + means J-Calibration only for APEX (dark orange) and Navis (purple) type floats. The result of SBE calibration for each sensor is shown as a line graph (7 conductivity/temperature points). Area within red dotted lines defines acceptable Argo accuracy, while the area within red dashed lines defines acceptable accuracy requiring re-calibration at least twice

system cannot be relied on for faulty sensor screening. Here, we evaluate the stability of calibration results for conductivity/salinity in J-Calibration and SBE-Calibration to quantify dispersions of conductivity measurements from all available experiments in our laboratory. We used 88 calibration experiments by J-Calibration conducted on 33 floats in 2017 and 83 calibration experiments by SBE-Calibration conducted on 18 floats in 2012-2017 (Table 10). Here, only one temperature point, $24^{\circ} \mathrm{C}\left(5.2 \mathrm{~S} \mathrm{~m}^{-1}\right)$, is used in SBE-Calibration and J-Calibration. We then calculate the root mean square (RMS) of conductivity differences from screening results based on SBE41 sensors that were calibrated twice or more. In order to confirm the accuracy of our results, the 83 calibration experiments performed on SBE-Calibration were generally conducted at least twice for each SBE41 sensor.

When $N$ times calibrations are conducted for each sensor, the difference of conductivity between SBE41 and SBE3 and 4 standard sensors is defined as $X_{M i}$, while the difference of conductivity from the last experiment for each sensor is $X_{B i}$, where $i$ is the number of experiments $(i=1 \sim N)$. The RMS of conductivity difference $\left(X_{\text {rep }}\right)$ between $X_{M i}$ and $X_{B i}$ is estimated as follows. 


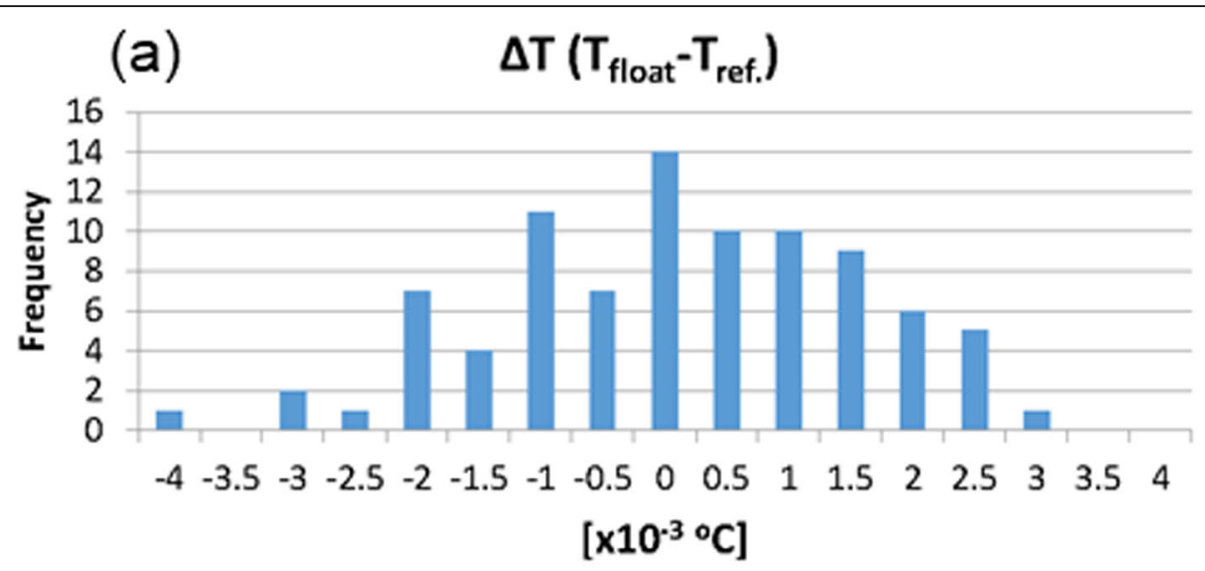

(b)

$\Delta \mathrm{C}\left(\mathrm{C}_{\text {float }}-\mathrm{C}_{\text {ref. }}\right)$

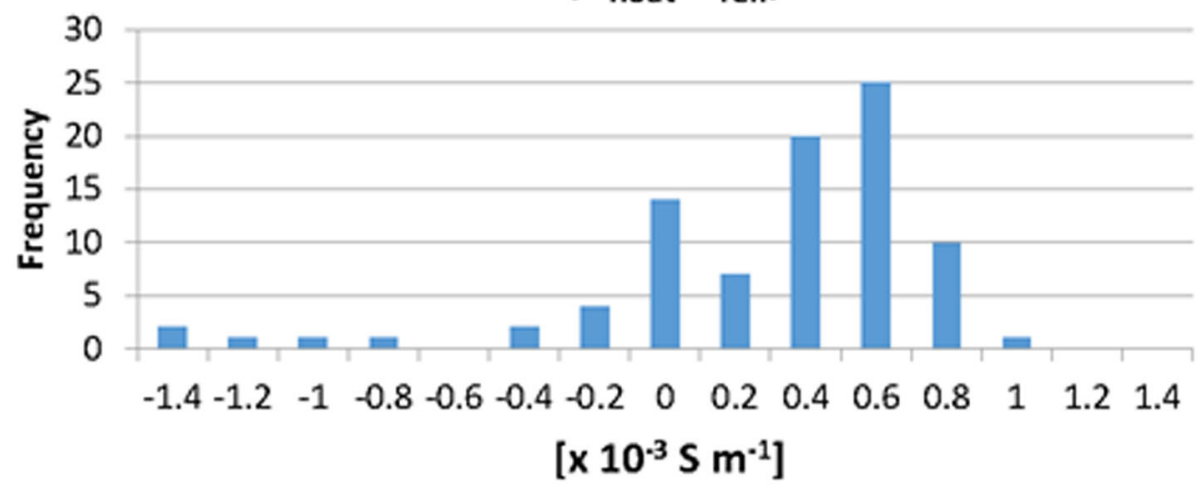

(c)

$\Delta \mathrm{S}\left(\mathrm{S}_{\text {float }}-\mathrm{S}_{\text {ref. }}\right)$

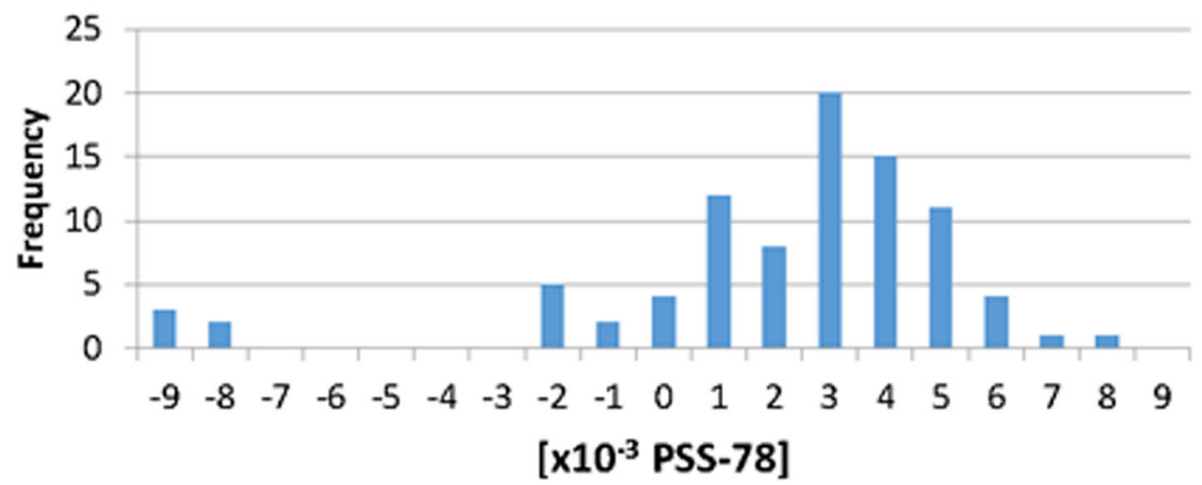

Fig. 11 Histograms of differences for temperature (a), conductivity (b), and salinity (c) on J-Calibration experiments. The number of experiments is 88 , binning $0.5 \times 10^{-3}{ }^{\circ} \mathrm{C}, 0.2 \times 10^{-3} \mathrm{~S} \mathrm{~m}^{-1}$, and $1 \times 10^{-3} \mathrm{PSS}-78$ widths, respectively. Averages of $\Delta \mathrm{T}, \Delta \mathrm{C}$, and $\Delta \mathrm{S}$ are $-1.5 \times 10^{-3}{ }^{\circ} \mathrm{C}, 0.19 \times 10^{-3} \mathrm{~S}$ $\mathrm{m}^{-1}$, and $1.6 \times 10^{-3} \mathrm{PSS}-78$, respectively. Standard deviations of $\Delta \mathrm{T}, \Delta \mathrm{C}$, and $\Delta \mathrm{S}$ are $1.44 \times 10^{-3}{ }^{\circ} \mathrm{C}, 0.48 \times 10^{-3} \mathrm{~S} \mathrm{~m}^{-1}$, and $3.3 \times 10^{-3} \mathrm{PSS}-78$, respectively. The experiments for some of SBE41 sensors are conducted for more than twice 


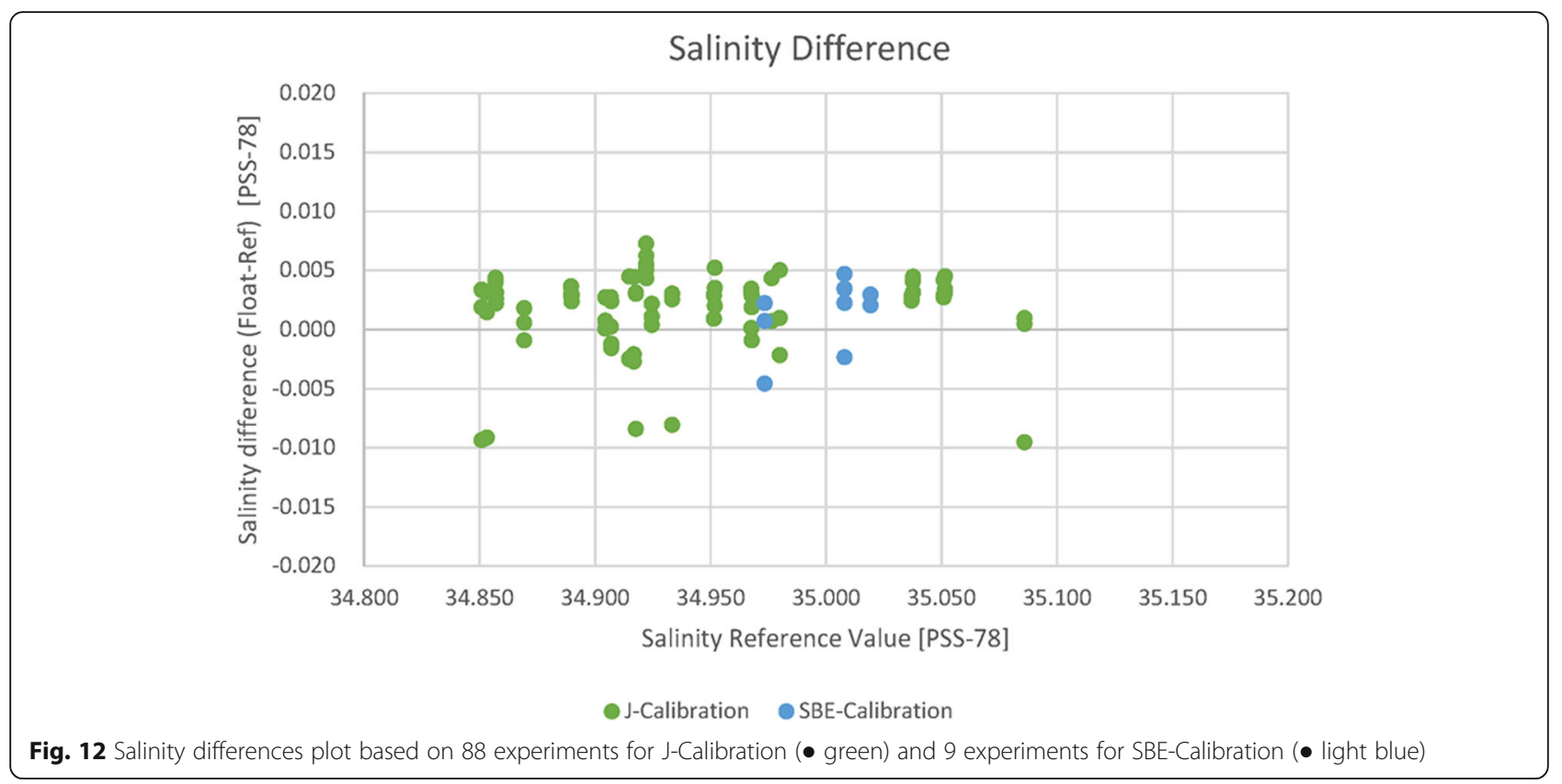

$$
X_{\text {rep }}=\sqrt{\frac{1}{n}\left(\sum_{i=1}^{N} X_{M i}-X_{B i}\right)^{2}}
$$

Here, the $X_{\text {rep }}$ is referred to as frequent RMS (F-RMS). Since the F-RMS can be analyzed for SBE-Calibration $\left(X_{\text {rep_SBE }}\right)$ and J-Calibration $\left(X_{\text {rep }_{-} J}\right)$, the difference of conductivity dispersions between both systems is estimated by the following equation.

$$
\Delta X_{\text {rep }}=X_{\text {rep_J }}-X_{\text {rep_SBE }}
$$

Histograms of F-RMS in SBE-Calibration and JCalibration are shown in Fig. 14 and their statistical values are summarized in Table 11. The histograms of F-RMS in J-Calibration (88 in total) tend to be close to 0, while that of SBE-Calibration (83 in total) is a little larger, which can be seen in the average, median, and standard deviation. Based on the result of F-RMS, the reliability of the screening result seems to be more J-Calibration than SBE-Calibration due to smaller dispersion. Although the laboratory environments and seasons are different between the two screening experiments, J-Calibration provides the same stability as SBE-Calibration based on the F-RMS results.

\section{Evaluation of J-Calibration based on QCed deployed float data}

Argo data quality control is generally carried out with nearby shipboard CTD data and other Argo float data to validate the Argo float data and to place a rQC and $\mathrm{dQC}$ flag, based on the rQC and $\mathrm{dQC}$ procedures as mentioned in the "Introduction" section. Here, we confirm whether the results of J-Calibration are appropriate to compare with the results of Argo float quality control. Although the dQC described in the "Introduction" section is conducted after 6 months $\sim 1$ year to check whether the Argo data meets its criteria, we carried out the same dQC procedures within 6 months to check the result of J-Calibration. However, we cannot address the issue of long-term drift in conductivity data using this method.

Table 12 shows a status list of deployed floats which had J-Calibration conducted in advance, the number of which is 16 of 33 floats until August 2018. As a result, all 16 floats conducting J-Calibration can be validated using the results of the data quality check. Regarding S/ N 8262 (WMOID 2903348) and 8263 (2903349), the data quality check can be completed after profile no. 17 , and the quality of data was found to be within the range of the Argo criteria. This indicates that the results of JCalibration are appropriate, although the first profile in both floats was not collected. Regarding S/N 414 (WMOID 2902974) and 672 (5905056), the data quality check can be done from profile no. 1 even though there was a buoyancy system failure, as the ability to obtain healthy data was not impaired. S/N 415, 416, and 417 are labeled as "positive salinity drift" or "gray list," as these profiles are out of range of Argo accuracy and uncorrectable within the framework of Argo data flow. Profiles which were within the Argo accuracy criteria for at least the before profile were nos. 

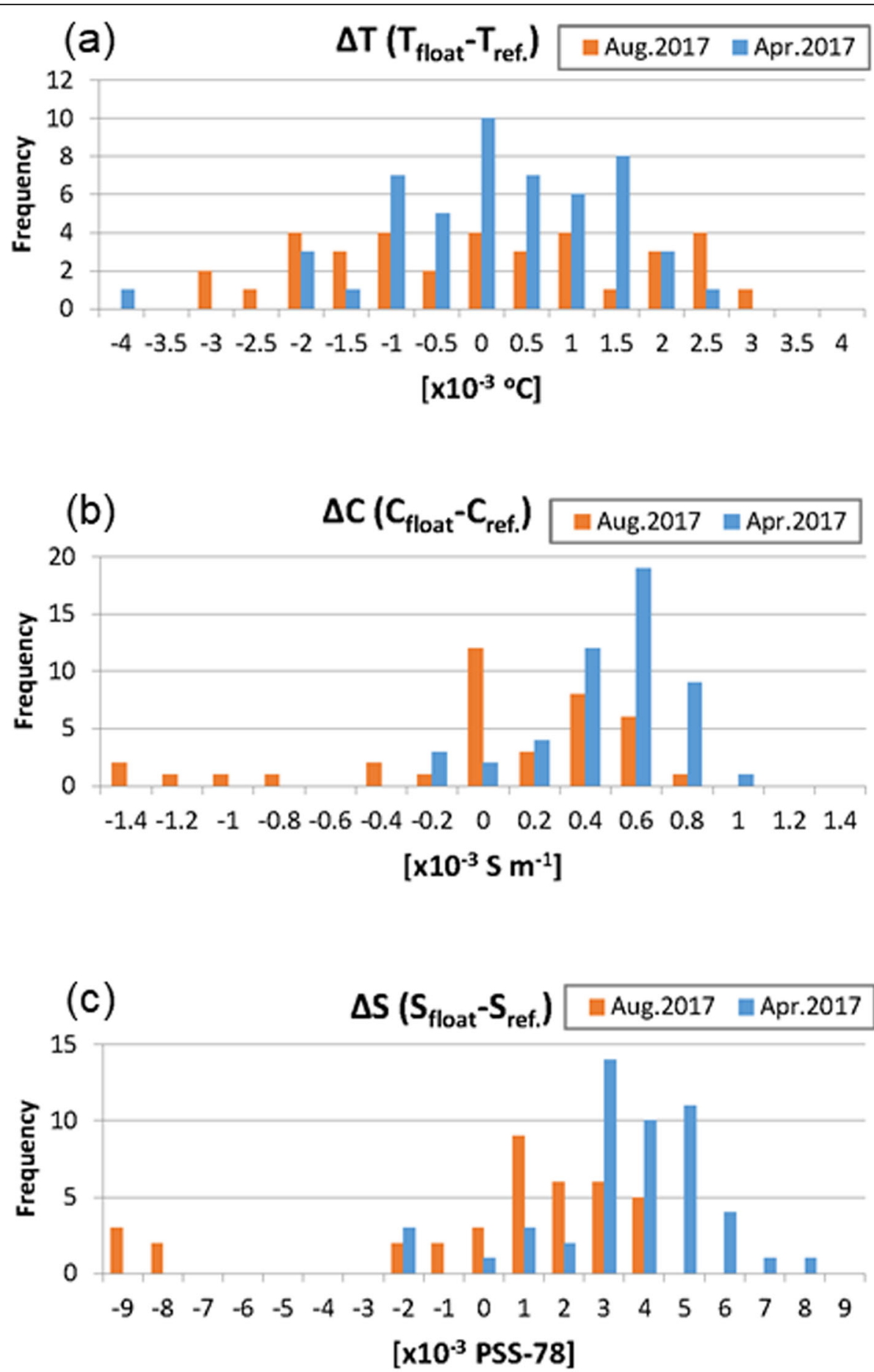

Fig. 13 Histograms of differences for temperature (a), conductivity (b), and salinity (c) in different seasons (April, winter; August, summer) in all 88 experiments of J-Calibration. Averages of $\Delta \mathrm{T}, \Delta \mathrm{C}$, and $\Delta \mathrm{S}$ in April/August are $-0.00009 /-0.00023^{\circ} \mathrm{C}, 0.00035 /-0.000004 \mathrm{~S} \mathrm{~m}^{-1}$, and $0.00282 /-$ 0.00012 PSS-78, respectively. Standard deviations of $\Delta \mathrm{T}, \Delta \mathrm{C}$, and $\Delta \mathrm{S}$ in April/August are $0.00124 / 0.00171{ }^{\circ} \mathrm{C}, 0.00032 / 0.00057 \mathrm{~S} \mathrm{~m}{ }^{-1}$, and 0.00224 / 0.00381 PSS-78, respectively

30,39 , and 20, respectively. Since we can judge that such error profiles with salinity drift or on the gray list are posteriori errors, the results of J-Calibration for the three floats are still appropriate. Although it is necessary to judge accuracy by comparing JCalibration results with dQC Argo float data for 
Table 10 Information of used data of SBE-Calibration and JCalibration to estimate F-RMS

\begin{tabular}{lll}
\hline & SBE-Calibration & J-Calibration \\
\hline Float type & Arvor (nke inc) & Navis (SBE), APEX (TWR) \\
$\begin{array}{l}\text { No. of examined } \\
\text { floats }\end{array}$ & 18 & 33 \\
$\begin{array}{l}\text { No. of calibration } \\
\text { test }\end{array}$ & 83 & 88 \\
$\begin{array}{l}\text { Frequency of } \\
\text { calibration test }\end{array}$ & 61 & 27 \\
Period & April 11, 2012-February 8, & $\begin{array}{l}\text { August 14, 2017-August } \\
\text { 24, 2017 }\end{array}$ \\
& 2013 &
\end{tabular}

greater than 6 months, the results indicate that salinity values are still satisfied within the Argo accuracy criteria in all normal operational floats without any software/hardware failure in temperature and salinity.

Therefore, we conclude that the results of JCalibration correspond to that of the dQC process, suggesting that J-Calibration is effective to avoid deployment of the Argo float with faulty sensors.

\section{Diagnostic of small positive salinity bias appeared in J- \\ Calibration results}

The small positive salinity bias $\left(+0.2 \sim 0.4 \times 10^{-3} \mathrm{~S} \mathrm{~m}^{-1}\right)$ in J-Calibration $(<0.01$ PSS-78) shown in Fig. 10 is diagnosed in this section. We conducted calibration of SBE3 and 4 standard sensors of temperature and salinity by returning any with faults to the manufacturer SBE every year. After the calibration by the manufacturer, coefficients of calibration functions are occasionally modified based on the calibration of SBE.

The amount of salinity sensor drift based on the manufacturer's calibration is -0.0048 PSS-78. Since the calibration was carried out in November 2018, the period of J-Calibration (April and August 2018) is about a half year before the manufacturer's calibration, and the amount of salinity bias correction is considerable at -0.0024 PSS-78 if we assume that this value was drifting linearly for a year. Therefore, the standard conductivity sensor had a negative bias. As a result, it is possible to that about a half of the total positive salinity bias is from standard sensors (average in +0.0033 PSS-78), suggesting that the method of J-Calibration is still appropriate even though it includes negative bias from the standard sensors. However, a small positive bias still remained. We also checked and monitored the possibility of a very small change in salinity concentration during the flow of artificial seawater through the tubes using the auto salinometer "Autosal" (Guildline instruments 1981). However, this did not detect any significant salinity bias that could explain the positive salinity bias. Further investigation of the salinity bias is required to improve the J-Calibration system.

\section{Possible applications to other fields}

All Earth Sciences fields encounter similar themes of difficulty in collecting high-quality and accurate data which can capture and reflect subtle changes over a long period of time. To implement such large-scale

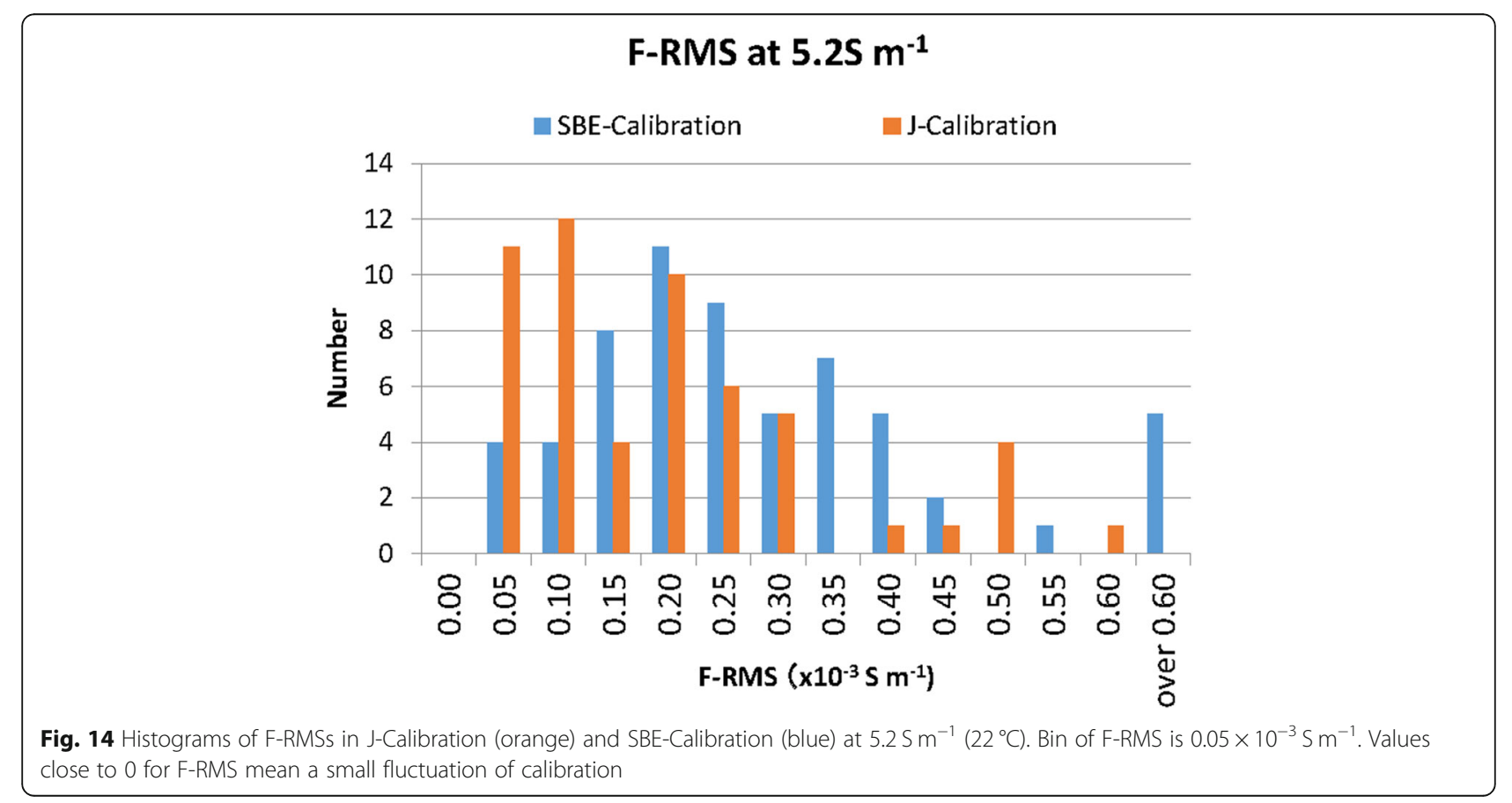


Table 11 Statistical values of F-RMSs for SBE-Calibration and J-Calibration

\begin{tabular}{llllll}
\hline & No. of experiments & No. of floats & Average $\left(\times 10^{-3} \mathrm{~S} \mathrm{~m}^{-1}\right)$ & Median $\left(\times 10^{-3} \mathrm{~S} \mathrm{~m}^{-1}\right)$ & Standard deviation $\left(\times 10^{-3} \mathrm{~S} \mathrm{~m}^{-1}\right)$ \\
\hline SBE-Calibration & 61 & 18 & 0.27 & 0.23 & 0.22 \\
J-Calibration & 27 & 33 & 0.20 & 0.18 & 0.17
\end{tabular}

observations, the use of autonomous observation robots is effective for decreasing human resources and costs, although this does introduce the possibility of hardware or software errors. Also, this technology is required to operate under extreme environments such as in the deep ocean which has high pressures and low temperatures. These extreme elements also introduce the complication of mechanical failures. Therefore, all of these factors could decrease the reliability of the collected data resulting in inaccurate conclusions. To avoid misleading data, quality management must be employed. This was the goal of our development of a calibration system such a J-Calibration which could introduce pre-deployment calibration.

We have shown J-Calibration to be effective in decreasing the time needed to achieve calibration and to not require the detachment of the CTD sensor unit from the Argo float, thereby avoiding float warranty issues. As well, J-Calibration is non-inferior to SBE-Calibration with respect to accuracy. We hope that the methods and investigations which we have demonstrated in developing this calibration method, such as international collaboration and collaboration between the user and the manufacturer, can be extrapolated to other fields in Earth Sciences.

\section{Conclusions}

We developed an efficient method of pre-deployment calibration for the SBE41 CTD sensor (J-Calibration). In comparison with the previous standard calibration method that is normally operated by the SBE manufacturer, there are some advantages. That is, no need for specially skilled technicians, shorter time for calibration, and increased efficiency, summarized in Table 13. The development is successful in that the screening procedure of SBE41 sensors is more efficient than before, and it is therefore possible to screen a larger number of sensors. An important consideration in the

Table 12 List of deployed floats and their status that J-Calibration has been conducted (as of August 29, 2019)

\begin{tabular}{|c|c|c|c|c|c|c|c|}
\hline Type & Float no. & WMO ID & Sensor S/N & Deployment date & Deployment position & Profile no. & Data quality check \\
\hline APEX & 7907 & 5905231 & 8530 & May 17, 2018 & $21.3 \mathrm{~N}, 176.5 \mathrm{E}$ & 48 & Healthy data in normal operation. \\
\hline APEX & 8084 & 2903211 & 9344 & October 4, 2017 & $38.0 \mathrm{~N}, 145.0 \mathrm{E}$ & 71 & Healthy data in normal operation. \\
\hline APEX & 8085 & 2903346 & 9345 & May 20, 2018 & $30.0 \mathrm{~N}, 151.0 \mathrm{E}$ & 49 & Healthy data in normal operation. \\
\hline APEX & 8086 & 2903347 & 9348 & May 23, 2018 & $24.0 \mathrm{~N}, 165.0 \mathrm{E}$ & 48 & Healthy data in normal operation. \\
\hline APEX & 8262 & 2903348 & 9444 & May 26, 2018 & $32.4 \mathrm{~N}, 146.1 \mathrm{E}$ & 47 & $\begin{array}{l}\text { Healthy data in normal operation except for } \\
\text { prof. no. } \sim 17 \text { which were no delivered data } \\
\text { due to float trouble. }\end{array}$ \\
\hline APEX & 8263 & 2903349 & 9465 & May 28, 2018 & $39.5 \mathrm{~N}, 145.5 \mathrm{E}$ & 46 & $\begin{array}{l}\text { Healthy data in normal operation except for } \\
\text { prof. no. } 17 \text { which were no delivered data } \\
\text { due to float trouble. }\end{array}$ \\
\hline Navis & 414 & 2902974 & 6167 & June 10, 2016 & $40.1 \mathrm{~N}, 170.0 \mathrm{E}$ & 285 & $\begin{array}{l}\text { Healthy data but unstable control due to } \\
\text { buoyancy system failure. }\end{array}$ \\
\hline Navis & 415 & 5905051 & 6128 & February 20, 2017 & $58.0 \mathrm{~S}, 126.0 \mathrm{~W}$ & 92 & $\begin{array}{l}\text { Healthy data but positive salinity drift after } \\
\text { prof.no. } 30 \text {. }\end{array}$ \\
\hline Navis & 416 & 4902368 & 6236 & July 17, 2016 & $50.6 \mathrm{~N}, 144.8 \mathrm{~W}$ & 115 & $\begin{array}{l}\text { Healthy data but flagged in gray list after } \\
\text { prof. no. } 39 .\end{array}$ \\
\hline Navis & 417 & 4902369 & 6151 & July 16, 2018 & $51.0 \mathrm{~N}, 148.4 \mathrm{~W}$ & 114 & $\begin{array}{l}\text { Healthy data but positive salinity drift after } \\
\text { prof. no. } 20 \text {. }\end{array}$ \\
\hline Navis & 583 & 5905050 & 7507 & August 21, 2016 & $6.1 \mathrm{~N}, 165.0 \mathrm{E}$ & 111 & Healthy data in normal operation. \\
\hline Navis & 584 & 5905221 & 7624 & March 1, 2018 & $17.0 \mathrm{~N}, 140.3 \mathrm{E}$ & 260 & Healthy data in normal operation. \\
\hline Navis & 588 & 5905060 & 7955 & September 20, 2017 & $23.0 \mathrm{~N}, 170.0 \mathrm{E}$ & 167 & Healthy data in normal operation. \\
\hline Navis & 628 & 5905059 & 8002 & September 14, 2017 & $21.5 \mathrm{~N}, 170.0 \mathrm{~W}$ & 167 & Healthy data in normal operation. \\
\hline Navis & 672 & 5905056 & 8086 & August 1, 2017 & $17.0 \mathrm{~N}, 149.0 \mathrm{E}$ & 345 & $\begin{array}{l}\text { Healthy data but unstable control due to } \\
\text { buoyancy system failure. }\end{array}$ \\
\hline Navis & 675 & 5905058 & 8091 & August 31, 2017 & $23.0 \mathrm{~N}, 150.0 \mathrm{~W}$ & 170 & Healthy data in normal operation. \\
\hline
\end{tabular}


Table 13 Comparison of work time and difficulty of JCalibration and SBE-Calibration. Unit is hours

\begin{tabular}{lll}
\hline & J-Calibration & SBE-Calibration \\
\hline Preparation & 1 & 4 \\
Calibration & 0.5 (1 point) & 14 (7 point) \\
Post-calibration & 0.5 & 6 \\
Total & 2 & 24 \\
Difficulty & Simple & Difficult \\
\hline
\end{tabular}

development is that the temperature of calibration is changed from 7 to 1 based on our experiences. As it is necessary to deploy a large number of 800 Argo floats to achieve sustainability under the framework of the international Argo program, the J-Calibration system is advantageous as it helps to avoid the deployment of floats with faulty sensors. Another point is to control room and water temperature appropriately during calibration experiments by applying some devices and materials. Those applications help the JCalibration system to become stable and to improve its accuracy.

On the other hand, some improvements in JCalibration still remain. For example, a small positive bias is still observed in comparison with SBECalibration as described in the "Results" and "Discussion" sections. Although correction of standard sensor bias is done with a half positive bias, further investigation of the J-Calibration system is needed to improve the system.

As technical progress is ongoing with the Argo floats, the Argo community recognizes more than previously that checks of Argo floats and screening of sensors before deployment are both important to improve and maintain the global Argo array. Continued improvements will require discussion with scientists, technicians, and manufacturers in the Argo Technical workshop (King et al. 2017). An efficient system for SBE41 users, like J-Calibration, must be broadly used in the Argo community and its standardization will be required in the near future. Further, with the improvement and promotion of pre-calibration systems such as J-Calibration, the volume of erroneous data will decrease and small climate signals in the ocean will be detected more accurately. This will make a significant contribution to our knowledge of climate change and the accuracy of climate change predictions.

\section{Abbreviations}

ALACE: Autonomous Lagrangian circulation explorer; CTD: Conductivity, Temperature, and Depth device; dQC: Delayed mode quality control; FRMS: Frequency of root mean square; RMS: Root mean square; rQC: Realtime mode quality control

\begin{abstract}
Acknowledgements
We would very much like to thank Dr. D. Murphy from Sea Bird Scientific for providing important ideas for J-Calibration and for his knowledge of SBE41 and the standard sensors. We thank Dr. S. Riser and Dr. D. Swift at the University of Washington and Dr. G. Johnson at the National Oceanographic and Atmospheric Administration (NOAA) Pacific Marine Environmental Laboratory (PMEL) for giving detailed information regarding the screening system. Dr. E. Steffen at the NOAA gave important advice. We also appreciate the technicians of Marine Works Japan LTD for their discussion about data management of Argo data and Argo float check. Finally, we greatly acknowledge the editor and all reviewers for a long time work for the professional review.
\end{abstract}

\section{Authors' contributions}

$\mathrm{SH}$ proposed the topic, conceived, and designed the study. $\mathrm{MH}$ developed the system and organized the technicians for the experimental study. TH carried out the experiments, suggested the modification of system, and analyzed the data. SA helped to construct the system, carried out the experiments, and analyzed the data. NK supported the experiments and analyses. All authors read and approved the final manuscript.

\section{Authors' information}

$\mathrm{SH}$ is a deputy group leader of JAMSTEC Argo and in charge of Argo float deployment and data management. $\mathrm{MH}$ is a technical staff of the Argo group in JAMSTEC, organizing the technicians of MWJ. TH is a chief technician of ocean instruments and supporting division, including Argo, in MWJ. SA and NK are technicians of ocean instruments of a supporting division, including Argo, in MWJ.

\section{Funding}

This work was supported by the research budget of the Japan Marine-Earth Science Technology.

\section{Availability of data and materials}

Data sharing is not applicable to this article as no datasets were generated or analyzed during the current study. Please contact the corresponding author for data requests.

\section{Competing interests}

The authors declare that they have no competing interests.

\section{Author details}

${ }^{1}$ Research Institute for Global Change, Japan Agency for Marine-Earth Science and Technology, 2-15 Natsushima-cho, Yokosuka, Kanagawa 237-0061, Japan. ${ }^{2}$ Marine Works Japan LTD., 3-54-1 Oppamahigashi, Yokosuka 237-0063, Japan.

Received: 13 February 2019 Accepted: 21 October 2019

Published online: 18 November 2019

\section{References}

Argo Data Management Team (2002) Report of the Argo data management meeting, In Proc. Argo Data Management Third Meeting, Ottawa http:// www.coriolis.eu.org/content/download/378/2871/file/Argo-DM-report-3rd. pdf. Accessed 18 Sept 2002

Argo Data Management Team (2012) Argo quality control manual Version 2.7. http://www.argodatamgt.org/content/download/341/2650/file/argo-qualitycontrol-manual-v2.6.pdf

Argo Science Team (1999) On the design and implementation of Argo: an initial plan for a global array of profiling floats, International CLIVAR Project Office Report 21, GODAE Report 5. GODAE International Project Office, Melbourne, p 32 http://www.argo.ucsd.edu/argo-design.pdf

Argo Steering Team (2018) 19th meeting of the International Argo Steering Team. http://www.argo.ucsd.edu/iast19.pdf. Accessed 12 Mar 2018

Argo Steering Team (2019) 20th meeting of the International Argo Steering Team. http://www.argo.ucsd.edu/iast20.pdf. Accessed 11 Mar 2019

Davis RE, Webb DC, Regier LA, Dufour J (1992) The autonomous Lagrangian circulation explorer (ALACE). J Atmospheric Oceanic Technol 9:264-285

Guildline Instruments (1981) Technical Manual for 'Autosal' Laboratory Salinometer Model 8400 
Jacobs SS, Giulivi CF (2010) Large multidecadal salinity trends near the PacificAntarctic continental margin. J Climate 23:4508-4524. https://doi.org/10. 1175/2010JCLI3284.1

Johnson GC, Toole JM, Larson NG (2007) Sensor corrections for sea-bird SBE41CP and SBE-41 CTDs. J Atmos Oceanic Technol 24:1117-1130. https://doi. org/10.1175/JTECH2016.1

King B, Riser S, Wijfels S (2017) Report from the 2nd float and CTD technical workshop. University of Washington, Seattle http://www.argo.ucsd.edu/ Report_floattechnicalworkshop_2017.pdf

Lyman J, Willis J, Johnson G (2006) Recent cooling of the upper ocean. Geophysical Res Lett:33. https://doi.org/10.1029/2006GL027033

Meyers G, White WB, Hasunuma K (1982) Annual variation in baroclinic structure of the northwestern tropical Pacific. Oceanographic Tropical 17: $59-69$

Oka E (2005) Long-term sensor drift found in recovered Argo profiling floats. J Oceanography 61(4):775-781. https://doi.org/10.1007/s10872-0050083-6

Purkey SG, Johnson GC (2010) Warming of global abyssal and deep Southern Ocean waters between the 1990s and 2000s: contributions to global heat and sea level rise budgets. J Climate 23:6336-6351. https://doi.org/10.1175/ 2010JCLI3682.1

Riser SC, Freeland HJ, Roemmich D, Wijfels S, Troisi A, Belbéoch M, Gilbert D, Xu J, Pouliquen S, Thresher A et al (2016) Fifteen years of ocean observations with the global Argo array. Nat Climate Change 5:145-153. https://doi.org/10. 1038/nclimate2872

Riser SC, Ren L, Wong A (2008) Salinity in Argo. Oceanography Spec Ed 21:1

Roemmich D, Boebel O, Desaubies Y, Freeland H, Kim K, King B, Le Traon PY, Molinari R, Owens BW, Riser S, Send U, Takeuchi K, Wijfels S (2001) Argo: the global Array of profiling floats. In: Koblinsky CJ, Smith NR (eds) Observing the oceans in the 21st century, GODAE Project Office. Bureau of Meteorology, Melbourne, pp 248-258

UNESCO (1978) Eighth report of the joint panel on oceanographic tables and standards. UNESCO technical papers in marine science 28

White W (1995) Design of a global observing system for gyre-scale upper ocean temperature variability. Prog Oceanography 36:169-217

Willis J, Lyman J, Johnson G, Gilson J (2008) In situ biases and recent ocean heat content variability. J Atmos Oceanic Technol:26. https://doi.org/10.1175/ 2008JTECHO608.1

Yokota M, Asai S, Hosoda S, Hirano M, Shikama N, Nagahama T, Fujisaki M (2007) Recalibration of temperature and conductivity sensors affixed on Argo floats. JAMSTEC Rep Res Dev 5:31-39

\section{Publisher's Note}

Springer Nature remains neutral with regard to jurisdictional claims in published maps and institutional affiliations.

\section{Submit your manuscript to a SpringerOpen ${ }^{\circ}$ journal and benefit from:}

- Convenient online submission

- Rigorous peer review

- Open access: articles freely available online

- High visibility within the field

- Retaining the copyright to your article

Submit your next manuscript at $\boldsymbol{\nabla}$ springeropen.com 